Anales de Geografía de la Universidad Complutense ISSN: 0211-9803

http://dx.doi.org/10.5209/AGUC.66939

\title{
Transformaciones geodemográficas en la Costa Blanca (Alicante): Relación entre segregación residencial de la población extranjera y precio de la vivienda ${ }^{1}$
}

\author{
Ernesto Cutillas Orgilés ${ }^{2}$
}

Recibido: 23 de mayo del 2018 / Enviado a evaluar: 7 de febrero del 2019 / Aceptado: 17 de octubre del 2019

Resumen. En este artículo se describen las transformaciones recientes en la composición de la población extranjera residente en la Costa Blanca y su diferenciación residencial. Se realiza un análisis temporal de quince años y se utilizan diferentes fuentes para caracterizar a distinta escala geográfica los patrones de localización y segregación de los extranjeros según las principales nacionalidades y el precio medio por metro cuadrado de la vivienda. Se consideran los municipios de Torrevieja y Benidorm como modelos de referencia en cuanto a la existencia de diferentes tipologías urbanas y por la presión inmobiliaria que han registrado en los últimos años. Los resultados manifiestan que a escala provincial existe una ligera relación positiva entre precios elevados de la vivienda y presencia de población extranjera. A escala inframunicipal la diferenciación residencial de los extranjeros se asocia más con la disponibilidad de una oferta más numerosa de viviendas que con el precio de venta.

Palabras clave: Costa Blanca; extranjeros; segregación residencial; vivienda.

[en] Geodemographic transformations in the Costa Blanca (Alicante): Relation between the residential differentiation of the foreign population and housing prices

\footnotetext{
Abstract. This paper describes the recent transformations in the composition of the foreign nationals residing in the Costa Blanca and explores its residential differentiation. A longitudinal analysis of fifteen years is carried out based on multiple sources in order to characterize at different geographic scale patterns of location and segregation of foreigners according to the main nationalities and to average housing price per square meter. The municipalities of Torrevieja and Benidorm are considered as

1 E Este artículo se ha realizado en el marco del proyecto de investigación: RTI2018-096435-B-C21, "Ciudades Medias Españolas: Urbanizacion y Politicas Urbanisticas. 40 Años de Ayuntamientos Democraticos", proyecto financiado por el Ministerio de Ciencia, innovación y universidades.

2 Departamento de Geografía. Universidad de Alicante.

E-mail: ernesto.cutillas@ua.es
} 
reference models in terms of the existence of different urban typologies and of the real estate pressure they have registered in recent years. The results show that there is at the provincial level a slight positive relationship between high house prices and the presence of foreign population. But at the inframunicipal level, the residential differentiation of foreigners is associated more with the availability of a more numerous housing offer than with the price of sale.

Keywords: Costa Blanca; foreign population; segregation; housing.

\section{[fr] Transformations géodémographiques sur la Costa Blanca (Alicante):} relations sur la différenciation résidentielle de la population étrangère et le prix du logement

Résumé. Cet article décrit les transformations récentes dans la composition de la population étrangère résidentielle sur la Costa Blanca ainsi que sa différenciation résidentielle. Une analyse temporelle de quinze ans est réalisée et différentes sources sont utilisées pour caractériser les schémas de localisation et de ségrégation des étrangers à différentes échelles géographiques selon les nationalités principales et le prix moyen par mètre carré du logement. Les municipalités de Torrevieja et Benidorm sont considérées comme des modèles de référence en termes de différentes typologies urbaines et de la pression immobilière enregistrée ces dernières années. Les résultats montrent qu'il existe une corrélation légèrement positive entre les prix élevés des logements et la présence de la population étrangère au niveau des provinces. Au niveau du secteur de recensement, la différenciation résidentielle des étrangers est davantage associée à la disponibilité d'une offre plus large de logements qu'au prix de vente.

Mots clés: Costa Blanca; étrangers; ségrégation; logement.

Cómo citar. Cutillas Orgilés, E. (2019): Transformaciones geodemográficas en la Costa Blanca (Alicante): Relación entre segregación residencial de la población extranjera y precio de la vivienda. Anales de Geografía de la Universidad Complutense, 39(2), 255-285.

Sumario. 1. Introducción. La Costa Blanca, efectos demográficos en un territorio sometido a presión residencial. 2. Estructura, objetivo e hipótesis. 3. Metodología y fuentes. 4. Dinámica, estructura y distribución reciente de los extranjeros en la Costa Blanca. 5. Relación entre el precio de la vivienda y la localización de extranjeros. 6. Relación entre el precio de la vivienda y los lugares de residencia de la población extranjera a escala inframunicipal. Los ejemplos de Torrevieja y Benidorm. 7. Conclusiones. 8. Bibliografía.

\section{Introducción: La Costa Blanca, efectos demográficos en un territorio sometido a presión residencial}

Los municipios litorales de la provincia de Alicante han sido durante los últimos años el escenario de importantes transformaciones en la composición demográfica de sus poblaciones. Asociados a estos cambios, el envejecimiento de la población y la consolidación de la Costa Blanca como destino residencial, laboral o ambos a la vez de ciudadanos procedentes de otros países han sido decisivos para entender las repercusiones geodemográficas y los cambios en la dinámica y estructura poblacional de las últimas dos décadas. El crecimiento de la población en los municipios estudiados se inscribe, como sucede en otras regiones mediterráneas, en un entorno geográfico resultante de un sistema residencial integrado por sinergias demográficas, 
sociales, políticas y territoriales que condicionan los mercados y las preferencias residenciales. Siendo la demografía la dimensión que más influye en los patrones de consumo residencial y sobre el resto de elementos del sistema (Módenes, LópezColás: 2014:104-105).

Junto con el aumento de los movimientos espaciales de población vinculados a estilos de vida multilocales (Rodes, Rodríguez, 2018), los desplazamientos de commuters por razones laborales (Romaní, Casado-Diaz, Lillo-Bañuls, 2017: 707) o el envejecimiento demográfico de las poblaciones urbanas (García, Jiménez, 2016), cabe advertir otro hecho fundamental para comprender las trasformaciones espaciales más recientes que afectan en el litoral alicantino: la consolidación de un modelo de ocupación del territorio caracterizado por la segregación socioresidencial de sus habitantes, especialmente en las principales ciudades litorales y enclaves residenciales (Martí, Nolasco-Cirugeda, Serrano-Estrada, 2018). Se trata de los lugares que conforman la conurbación a partir de la cual se organiza el proceso urbanizador que se ha asociado con las actividades turísticas y que concentra las mayores densidades edificatorias y poblacionales de la provincia (Vera, Diez, 2016). Esta aglomeración ha resultado decisiva para entender el vertiginoso crecimiento de las áreas urbanas de los espacios litorales y pre-litorales, la significativa ocupación residencial y terciaria del periurbano y el cambio sociodemográfico en algunos espacios urbanos que fueron pioneros del desarrollo inmobiliario durante los últimos años del siglo pasado y principios de este. Constituye un claro exponente del modelo urbanizador valenciano que ha perseguido los tres tipos de economías clásicas: de escala, de aglomeración y urbana, al margen de principios de sostenibilidad, competitividad o gestión integral (Obiol, Pitarch, 2011: 196).

Teniendo en cuenta que las formas de convivencia y los tipos de hogares son más complejos en los lugares litorales especializados en actividades turísticas (González, 2008: 103); cabe advertir, en paralelo a los anteriores procesos, que son los espacios litorales de la provincia de Alicante donde mejor se visibiliza la persistencia de unos desequilibrios sociales y geodemográficos. Son lugares cuya población residente presenta unas estructuras demográficas más heterogéneas que en otros ámbitos provinciales, donde se registra una mayor diversidad en la dinámica demográfica de residentes, turistas y población vinculada, y en donde existe un importante mercado de edificación residencial, especialmente de segundas viviendas. Ahora bien, en el caso de la Costa Blanca alicantina cabe situar en este contexto los cambios que desde hace unas décadas se observan en la mayor diversificación de los lugares de procedencia de los extranjeros empadronados, en unas pautas postfordistas en la ocupación del territorio basadas en la segmentación y densificación de los destinos turísticos preexistentes (Vera, Baños, 2010: 342) y en el notable incremento de la segunda residencia (Morote; Hernández, 2016: 56). Y todo ello al amparo del importante incremento del sector de la construcción que se ha orientado, por un lado, a la obra pública y, por otro lado, a la promoción y construcción de viviendas destinadas al mercado inmobiliario local, nacional e internacional. 
Dichos procesos se han visto materializados al existir una vinculación causal entre el desarrollo del urbanismo expansivo y el aumento del turismo residencial (Membrado Tena, 2015: 261-262). Fenómeno controvertido, el del turismo residencial, que al margen de sus heterogéneas definiciones ha sido el instrumento al servicio de intereses que trascienden el análisis de la realidad social (Mantecón, 2017: 407), y a lo que añadiremos territorial. Pues sin duda, en los últimos años se ha podido constatar la prevalencia de un modelo inmobiliario-residencial en el que han confluido las expectativas de la demanda de viviendas para residentes temporales de otras partes de España y Europa (Amat, 2017: 346).

A raíz del estallido de la burbuja inmobiliaria surgida de la "década prodigiosa" del urbanismo español (Burriel, 2008) y de sus múltiples efectos derivados; como son la contracción en la construcción de nuevos inmuebles, la disminución en la compraventa de viviendas o la notable caída de población retirada procedente de destinos tradicionales de Europa del norte y central, entre otros, se ha conformado en pocos años una nueva composición de los extranjeros residentes en la Costa Blanca. Así, se puede identificar una serie de permanencias y de cambios en relación a las dinámicas socioterritoriales de la población, que ha desembocado en las actuales pautas de segregación territorial vinculadas al urban sprawl. A ello hay que añadir la propia madurez del destino, que obedece fundamentalmente a estrategias en la configuración de ofertas complementarias dirigidas a satisfacer los cambios del sector (Cànoves, Prat y Blanco, 2016: 432). Serían unos procesos que a distinta escala también se observan en otras regiones españolas, como es el caso de la Costa del Sol (Batista y Natera, 2013), de la Costa Dorada (Rovira y Antón-Clavé, 2014), de las Islas Baleares (Blázquez-Salom, Artigues, Yrigoy, 2015) o en las Islas Canarias (Díaz, Parreño y Domínguez, 2017), entre otras. Como señalan Sabater, Galeano y Domingo (2013: 34 ), son destinos con una fuerte orientación turístico-residencial que en el caso de Alicante concentra el mayor número de enclaves minoritarios de toda España: 72 de los 258 enclaves étnicos identificados.

\section{Estructura, objetivos e hipótesis}

El objetivo Este artículo tiene la siguiente estructura. En la primera parte se presenta el territorio objeto de estudio en relación a las aportaciones teóricas y procesos vinculados a la segregación residencial y la expansión urbana reciente, en este apartado también se formulan los objetivos de la investigación y la hipótesis sobre la que se fundamenta el trabajo. Sigue un segundo y tercer apartado en los que se establece el objetivo e hipótesis de la investigación, y se valoran las fuentes de información y la metodología empleada para contrastarlas con ejemplos de otros ámbitos geográficos. En cuarto y quinto lugar, se describe sucintamente la distribución, la estructura y la dinámica demográfica reciente de los extranjeros en el conjunto de la Costa Blanca. También se considera el reparto del precio medio de la vivienda entre los municipios del interior provincial y el litoral. El sexto apartado del artículo se centra en los municipios de Torrevieja y Benidorm para analizar los 
índices de segregación de las principales nacionalidades extranjeras, la distribución territorial diferencial de los distintos subgrupos de extranjeros entre sí y la correlación que mantiene el precio medio de la vivienda con la mayor o menor presencia de población extranjera. El último apartado se dedica a presentar las conclusiones del trabajo.

Conforme a lo anteriormente señalado, este trabajo presenta un doble objetivo. En primer lugar, registrar los cambios en la composición demográfica de la población extranjera empadronada en la Costa Blanca a comienzos de siglo. En segundo lugar, y a una doble escala de análisis, comprobar a nivel de municipio litoral y pre-litoral si existe una relación causal entre la presencia de colectivos de diversas nacionalidades y el precio medio de venta por metro cuadrado de vivienda. Dichos objetivos se enmarcan en el contexto del gran desarrollo inmobiliario de comienzos de siglo, que ha ido en paralelo a la concentración de los distintos colectivos de extranjeros en determinados enclaves residenciales de la Costa Blanca. Ante esta premisa inicial, cabe plantearse si ello implica un incremento de la segregación residencial de los residentes extranjeros, pues estos se localizan en algunos de los municipios que desde comienzos de siglo cuentan con las mayores concentraciones de esta población.

A partir de este planteamiento entenderemos la segregación residencial como la ausencia de interacción entre grupos sociales, y desde el punto de vista geográfico la segregación será el nivel de desigualdad espacial entre grupos de población en un mismo sistema urbano (Musterd, 2011: 362). Es en este punto cuando se puede considerar si las pautas espaciales de segregación afectan de igual manera a los distintos colectivos nacionales; al margen de que pueda existir población extranjera integrada (socialmente), pero que resida segregada (geográficamente), y al revés «Esta relación compleja entre el acceso a la vivienda, la geografía y la concentración de asentamientos étnicos pone en crisis la asunción que la concentración espacial representa automáticamente exclusión social o que la dispersión espacial conlleva la integración» (Arbaci, 2008: 13). Este hecho reviste suma importancia por la percepción que de esos lugares se tiene a nivel de discurso político, económico e incluso de gestión territorial, pues denota la relación que mantienen estas personas con la capacidad económica para acceder a la vivienda; pues siguiendo a Capel (1997), consideramos que las diferencias de renta, y en su caso el precio final que se paga por metro cuadrado de inmueble, es el mecanismo fundamental que explica la segregación socioresidencial entre comunidades. Dicho proceso (Wissink, Schwanen; van Kempen, 2016: 126-127) es, entre otros, el resultado de la discriminación respecto al acceso a la vivienda que reproduce las desigualdades de acceso a servicios $\mathrm{y}$, por ende, a la igualdad de oportunidades entre los residentes de ese territorio. En consecuencia, partimos de la base que en las ciudades especializadas en actividades turísticas y de servicios se suele producir una doble presión en los usos del suelo en ausencia de una aplicación adecuada de la regulación en el planeamiento urbano (Burriel, 2015). Pues, de un lado, la competencia que se produce entre las viviendas secundarias y otros usos terciarios impulsan un encarecimiento del precio de la vivienda en los espacios más atractivos y mejor conectados del sistema urbano; y, por 
otro lado, la presión laboral empuja a la población activa a buscar un lugar de residencia en espacios o municipios más alejados de los centros de trabajo.

\section{Metodología y fuentes}

Una parte significativa de los estudios acerca de la segregación residencial se ha nutrido de sólidos fundamentos teóricos como los aportados por Massey y Denton (1988) en relación a los indicadores para medir la igualdad, la exposición, la concentración, el reagrupamiento espacial y la centralidad de las distintas comunidades en el medio urbano. Con ese propósito Apparicio et al. (2014) han desarrollado varias versiones de un software de análisis aplicado a un sistema de información geográfica: Geo-segregation Analyzer, que se ha utilizado en este trabajo. Desde una perspectiva geográfica la aplicación empírica de los indicadores de segregación étnica o residencial cuenta con referentes muy destacados en la disciplina, es el caso del trabajo de Musterd, Ostendorf y Breebaart (1997) para Londres, París, Düsseldorf, Amsterdam, Frankfurt o Bruselas, o la investigación de Malheiros (2002) para ocho ciudades del norte y sur de Europa. En el caso de los ámbitos urbanos españoles destacan, entre otras, las aportaciones realizadas por especialistas vinculados al Centre d'Estudis Demogràfics (CED-UAB) y/o del campo de la Geografía. Por ejemplo, destacan los trabajos de Parreño y Domínguez para las ciudades de las Islas Canarias (2008), Parra (2010) para la ciudad de Sevilla, Bayona y López para Barcelona (2011), Roquer, Alberich y Muro (2013) para varias ciudades catalanas, Palacios y Vidal (2014) para Madrid, Barcelona y Sevilla o Natera (2015) para el caso de once ciudades andaluzas o la aportación de Batista y Natera (2018) para el caso de la ciudad de Málaga. Mediante técnicas de autocorrelación espacial y segregación de multigrupos, es frecuente identificar en estos trabajos concentraciones significativas de inmigrantes laborales o de primera generación en barrios con mayor existencia de viviendas en mal estado, antiguas o en alquiler; mientras que los extranjeros con mayor nivel educativo o posicionamiento social presentan pautas de localización más dispersas en el municipio, o en zonas con mejores condiciones residenciales.

En esta línea, existe literatura geográfica que indaga acerca de la inserción residencial de la inmigración internacional. Siguiendo a Módenes, Bayona y LópezColas (2013: 296-297) los estudios se centran bien en zonas urbanas en las que la vivienda actúa como un filtro en la distribución y segregación de esta población, o bien en asentamientos periurbanos más dispersos donde las características de la vivienda permiten analizar las condiciones de vida y posición social de los extranjeros. En ambos casos se discute si existe una jerarquía de extranjeros en el acceso a la vivienda según la nacionalidad; y, en el caso de existir, cuál es su magnitud teniendo en cuenta que, en España, a pesar de su alta segregación social, la segregación espacial es menor que en otros países europeos (Pareja-Eastaway, 2009).

A una escala de más detalle se han elegido para esta investigación los municipios de Torrevieja y Benidorm que, sin ser necesariamente representativos del conjunto de 
la Costa Blanca, tienen un notable peso demográfico y ejemplifican dos modelos de ocupación del territorio muy contrastados respecto de su entorno (mapa 2). Desde el punto de vista administrativo cuentan con el número suficiente de secciones censales (33 y 45) para poder aplicar las técnicas de análisis espacial requeridas con este tipo de metodologías. Torrevieja está situado en el sur de la provincia, es más extensivo en la ocupación del suelo residencial y dispone de una importante presencia de urbanizaciones de viviendas adosadas en parcelas reducidas. Benidorm se localiza en el norte de la provincia, es más intensiva la ocupación del suelo y cuenta con mayor oferta hotelera y de alquiler, que en los últimos años se ha visto complementada con urbanizaciones residenciales de baja densidad (Morote, 2014). Son dos ejemplos en los que, a través de sus indicadores de segregación residencial y del precio de venta por metro cuadrado, inferir hasta qué punto la nacionalidad y la potencial capacidad de gasto que se presupone a las distintas comunidades de extranjeros pueden influir en las pautas de ocupación del suelo residencial.

Los datos del padrón municipal de habitantes ofrecidos por el INE constituyen una de las fuentes consultadas en el artículo. Por el ámbito geográfico de la investigación no pueden obviarse los cambios introducidos por la Resolución de 16 de marzo de 2015, sobre instrucciones técnicas a los Ayuntamientos sobre la gestión del padrón municipal $^{3}$. Estas instrucciones surgen al observarse la existencia de sobrerregistros de colectivos de población comunitaria que ya no residían en municipios españoles, bien porque han regresado a sus países de origen, o bien porque las bajas por defunción no habían sido contrastadas con los registros civiles. El cruce de información entre las distintas administraciones ha permitido comprobar una reducción significativa de esta población a partir de 2016.

Otra limitación de las fuentes de información demográfica que afecta a esta investigación se deriva de la medición de los registros que relacionan el lugar de nacimiento de los residentes con la adquisición de la nacionalidad española o comunitaria. Es caso de los inmigrantes procedentes de países Latinoamericanos que tan solo requieren dos años de residencia legal para optar a la ciudadanía, frente a los diez años que necesitan otros extranjeros (Recaño; Jaúregui-Diaz, 2014). Más dificultades requeriría la consideración de una estimación fiable del subregistro de aquellos extranjeros que pasan largas temporadas y que no se empadronan. Incluiría una población flotante muy presente en toda la Costa Blanca para la que el INE, a través de la información censal de la población vinculada de 2001 y 2011, no ofrece información. Huete (2008: 79-80) apunta que su difícil cuantificación afecta a la

\footnotetext{
${ }^{3}$ Resolución de 16 de marzo de 2015, de la Subsecretaría, por la que se publica la Resolución de 30 de enero de 2015, de la Presidencia del Instituto Nacional de Estadística y de la Dirección General de Coordinación de Competencias con las Comunidades Autónomas y las Entidades Locales, sobre instrucciones técnicas a los Ayuntamientos sobre gestión del padrón municipal. Recuperado de https:/www.boe.es/eli/es/res/2015/03/16/(1)
} 
planificación de servicios e infraestructuras, especialmente porque muchos de estos "semi-residentes" se localizan en urbanizaciones aisladas de los núcleos urbanos.

En esta investigación se hace uso de la información padronal a distintas escalas geográficas junto con los datos que ofrece el portal inmobiliario Idealista.com sobre el precio de la vivienda residencial. La utilización de esta fuente ha sido posible a través del vaciado de información de los municipios estudiados y de la selección manual de las secciones censales identificadas en el visualizador del propio portal, que se hacen coincidir con las prexistentes. Se trata de una fuente alternativa que ha sido referenciada en otros trabajos de como los de Palacios (2008) para el conjunto de España, Donat (2012) en el área metropolitana de Barcelona o Yrigoy (2017), enfocado al alquiler turístico en la isla de Menorca y combinándola con la información de la plataforma airbnb. Pese a las limitaciones que pudieran derivarse de la utilización de la fuente, ésta permite una observación transversal que permite estimar en un momento dado el precio de los inmuebles en relación a los residentes. Dicho procedimiento viene a suplir la ausencia de información desagregada del precio de los inmuebles más allá de los datos procedentes del catastro u otro tipo de información sobre la vivienda que se recoge en el censo de viviendas del año 2001; y sobre todo de las muestras censales del año 2011. En ningún caso estas fuentes llegaron a ofrecer el promedio del precio medio de la vivienda a nivel de sección censal.

En nuestro caso este planteamiento permite construir un modelo explicativo con distintas fuentes de información que relaciona el precio de la vivienda respecto a los lugares con mayor diferenciación socioresidencial. Esto es un aspecto central de esta investigación ya que salvo los trabajos de Gónzalez y de Lázaro (2012) para Alcalá de Henares y León o el de Pujol-Perdices y Gutiérrez (2017) en la Pineda (Tarragona), son escasos los estudios procedentes de la Geografía que hayan relacionado a escala inframunicipal la concentración o la dispersión de los extranjeros en ciudades medias en relación con el precio medio por metro cuadrado de las viviendas (en alquiler o en propiedad). Y especialmente en aquellas ciudades que, como en el caso de la Costa Blanca, son destinos turísticos maduros. Pues para este ámbito geográfico han sido más frecuentes los estudios que se encargan de la diferenciación residencial de los subgrupos de extranjeros asociados a factores vinculados a las características del parque de viviendas u otras características sociodemográficas y habitacionales recogidas en los censos de población y viviendas. Así, destacan los estudios de carácter cualitativo de Mantecón, Huete y Mazón (2009), Huete y Matecón (2011) y Mantecón, Membrado y Huete (2016); o aquellos de corte más cuantitativos como el de Domínguez, Martí y Nolasco (2016) o Morote y Hernández (2016). En estas aportaciones subyacen planteamientos de análisis crítico y la utilización, con mayor o menor detalle, de fuentes de información de carácter secundario, ya sea ésta demográfica, territorial o inmobiliaria, aunque sin profundizar en la relación entre nacionalidades y diferenciación residencial. En cambio, con esta investigación se aporta la novedad de no emplear variables censales referidas a la antigüedad de las viviendas, la superficie, el estado de conservación o el régimen de tenencia, pues el tiempo transcurrido del censo más fiable de viviendas 
(año 2001) puede distorsionar los resultados esperados. Por ello se ha considerado la utilización de una fuente que continuamente se actualiza a escala inframunicipal (Idealista.com), y que permite su combinación con los datos del padrón continuo de cara a posibles estudios longitudinales. Es por ello que también, y a diferencia de otras aportaciones que caracterizan la segregación residencial de los extranjeros en ámbitos urbanos y metropolitanos, esta investigación introduce una diferencia notable debido a la especialización turístico-residencial y la práctica desestacionalización como destinos turísticos de los ejemplos seleccionados.

\section{Dinámica, estructura y distribución reciente de los extranjeros en la Costa Blanca}

En algo más de una década la dinámica de la población extranjera residente en la Costa Blanca ha experimentado notables fluctuaciones en la intensidad de las migraciones, con independencia de su lugar de procedencia o nivel de renta «British nationals and other European migrants from countries with higher levels of economic development than Spain are part of the same continuum of mobility types as foreign nationals from countries with lower levels of development» (Huete et al., 2013: 346). Ello se ha manifestado con periodos de intenso crecimiento a comienzos de siglo, seguidos de años con crecimientos más moderados, pasando por años con bruscos descensos para concluir con un repunte de nuevas llegadas que han supuesto una estabilización en el flujo de migrantes (figura 1). En valores relativos se ha pasado del $11,9 \%$ de extranjeros en 2002 a $23,6 \%$ en 2008, en el año 2013 se llega al máximo con el $24,1 \%$ y se concluye el periodo en el año 2017 con el 17,8\% de extranjeros (cuadro 1). Esta tendencia, en efecto, representa un reflejo de la trayectoria de los ciudadanos de origen extranjero que puede ser resultado del final de una evolución del estilo de vida, de las migraciones laborales, una tendencia a la contraurbanización, una característica demográfica o laboral (Salvà, 2011: 831); o simplemente el retorno al lugar de origen por alguna situación personal sobrevenida o por una decisión familiar.

$\mathrm{Si}$ a finales del siglo pasado e inicio de este, las nacionalidades extranjeras más numerosas en la provincia de Alicante eran aquellas que procedían de Europa Central (Reino Unido, Alemania, Países Bajos, Bélgica o Francia), los cambios en la composición de esta población, transcurridas casi dos décadas, han sido tan profundos como las transformaciones territoriales en los lugares de residencia. Pues en efecto, junto con los ciudadanos británicos, que continúan siendo los ciudadanos extranjeros más numerosos en la Costa Blanca (66.397 o el 20,4\% del total de extranjeros), se consolidan marroquíes, rumanos y rusos como los siguientes extranjeros con mayor presencia en la región, concretamente el $11,7 \%, 7,6 \%$ y $4,9 \%$, respectivamente (cuadro 1). 
Figura 1. Evolución de la población extranjera en la provincia de Alicante 2002-2017

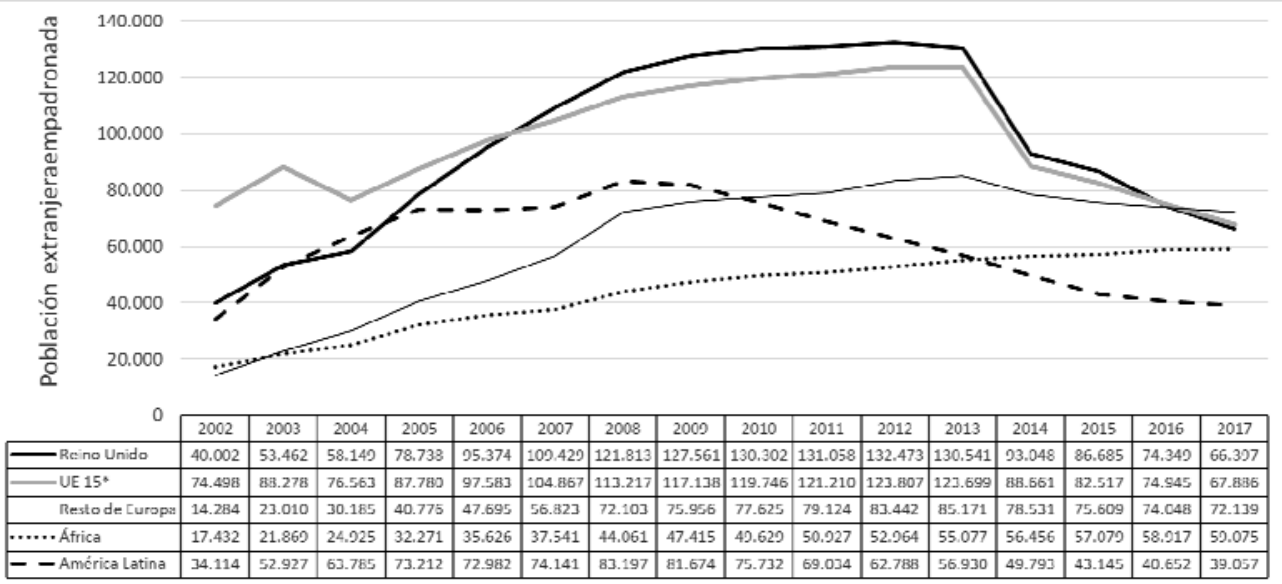

Fuente: INE. Padrón municipal de habitantes a 1 de enero. Elaboración propia.

El resultado de los cambios en la composición de la población extranjera y su relativo aumento tras un periodo de descensos, permite reflexionar acerca de cómo ha evolucionado la distribución de estos residentes durante el periodo estudiado en los municipios de la provincia (mapa 1 y 2). Tomando los residentes británicos como referencia de migración de retiro, se observan durante este periodo importantes incrementos de población, llegando a registrar su máximo en el año 2012 con 132.473 personas en el conjunto de la provincia. Sin embargo, en poco menos de cinco años esa cifra se ha reducido hasta más de la mitad en 2017. Dicha dinámica demográfica observada en un intervalo tan corto de tiempo, junto con unas estructuras demográficas más regresivas de este colectivo (figura 2), es un fenómeno consustancial del envejecimiento demográfico que desde hace varios años se viene constatando entre los de extranjeros retirados en la Costa Blanca (La Parra; Mateo, 2008). Lo que permite plantearse si a corto o medio plazo, esta comunidad de residentes seguirá manteniendo el mismo peso demográfico o económico que ha tenido hasta los últimos años, especialmente hasta comienzos del año 2021 que finaliza la transición por la que se fija la salida del Reino Unido como estado miembro de la Unión Europea. Algo similar sucede con los ciudadanos procedentes de Alemania, que en 2002 suponían la segunda nacionalidad extranjera más numerosa de la provincia; y que, transcurridos quince años han pasado de 26.611 residentes a 14.285. Ha descendido el número de residentes casi hasta la mitad, lo que sin dudas tiene repercusiones en la composición demográfica de los enclaves localizados en

\footnotetext{
${ }^{4}$ En UE $15^{*}$ se incluyen las nacionalidades extranjeras de los países que integraban la UE hasta 2004 más Suiza y Noruega (se excluye el Reino Unido).
} 
urbanizaciones a medio camino del turismo y de la migración residencial, y que caracterizan una parte significativa del litoral alicantino (Sabater, Galeano, Domingo, 2013: 26). Para ambas nacionalidades, los descensos en la variación relativa del periodo 2013-2017 han sido más intensos que los registrados para cualquiera de las otras nacionalidades consideradas (cuadro 1).

Cuadro 1. Cambios en la composición de las principales nacionalidades extranjeras en la Costa Blanca 5 .

\begin{tabular}{|c|c|c|c|c|c|c|c|c|c|c|c|}
\hline \multirow[t]{2}{*}{$\begin{array}{l}\text { Principales } \\
\text { nacionalidad } \\
\text { es } \\
\text { extranjeras }\end{array}$} & \multicolumn{4}{|c|}{ Volumen total de residentes } & \multicolumn{4}{|c|}{$\begin{array}{l}\text { Valor porcentual de los } \\
\text { residentes respecto la } \\
\text { población extranjera }(\%)\end{array}$} & \multicolumn{3}{|c|}{$\begin{array}{l}\text { Variación relativa } \\
\text { acumulada de la } \\
\text { población residente } \\
\text { en varios periodos } \\
(\%)\end{array}$} \\
\hline & 2002 & 2008 & 2013 & 2017 & 2002 & 2008 & 2013 & 2017 & 02-08 & 08-13 & $13-17$ \\
\hline Reino Unido & 40.002 & 121.813 & 130.541 & 66.397 & 21,5 & 27,3 & 27,8 & 20,4 & 204,5 & 7,2 & $-49,1$ \\
\hline Marruecos & 10.958 & 30.395 & 36.692 & 38.106 & 5,9 & 6,8 & 7,8 & 11,7 & 177,4 & 20,7 & 3,9 \\
\hline Rumania & 1.989 & 30.165 & 34.037 & 24.779 & 1,1 & 6,8 & 7,3 & 7,6 & $1.416,6$ & 12,8 & $-27,2$ \\
\hline Rusia & 4.057 & 7.912 & 12.969 & 15.844 & 2,2 & 1,8 & 2,8 & 4,9 & 95,0 & 63,9 & 22,2 \\
\hline Argelia & 4.196 & 7.795 & 11.854 & 15.104 & 2,3 & 1,7 & 2,5 & 4,6 & 85,8 & 52,1 & 27,4 \\
\hline Alemania & 26.611 & 35.395 & 35.916 & 14.285 & 14,3 & 7,9 & 7,7 & 4,4 & 33,0 & 1,5 & $-60,2$ \\
\hline Colombia & 12.964 & 20.667 & 13.826 & 9.288 & 7,0 & 4,6 & 2,9 & 2,9 & 59,4 & $-33,1$ & $-32,8$ \\
\hline Ecuador & 11.172 & 23.997 & 15.150 & 8.021 & 6,0 & 5,4 & 3,2 & 2,5 & 114,8 & $-36,9$ & $-47,1$ \\
\hline Resto & 73.684 & 168.229 & 178.432 & 133.296 & 39,7 & 37,7 & 38,0 & 41,0 & 128,3 & 6,1 & $-25,3$ \\
\hline $\begin{array}{l}\text { TOTAL } \\
\text { Extranjeros }\end{array}$ & 185.633 & 446.368 & 469.417 & 325.120 & $\begin{array}{l}(\%) \\
\text { resp }\end{array}$ & $\begin{array}{l}\text { blac } \\
\text { a la }\end{array}$ & $\begin{array}{l}\text { extra } \\
\text { blaci }\end{array}$ & & 140,5 & 5,2 & $-30,7$ \\
\hline $\begin{array}{l}\text { TOTAL } \\
\text { Población }\end{array}$ & 1.557 .587 & 1.891 .477 & 1.945 .642 & 1.825 .443 & 11,9 & 23,6 & 24,1 & 17,8 & 21,4 & 2,9 & $-6,2$ \\
\hline
\end{tabular}

Fuente: INE. Padrón municipal de habitantes a 1 de enero. Elaboración propia

\footnotetext{
${ }^{5}$ Se ha incluido en este cuadro a los nacionales procedentes de Colombia y Ecuador para señalar que la tercera y cuarta nacionalidad extranjera más numerosa de 2002 ocupa en 2017 la décima y decimotercera posición, respectivamente. Según los datos del padrón continuo de 2002 de los 13.613 y 11.216 nacidos en Colombia y Ecuador, respectivamente, sólo tenían la nacionalidad española 613 y 162 personas procedentes de ambos países. Para el año 2017 de los 22.554 y 18.918 nacidos en Colombia y Ecuador, han adquirido la nacionalidad española 13.071 y 11.512 personas. Dichas magnitudes dan una muestra del arraigo de estos ciudadanos y de la trascendencia que tienen en el tejido social, cultural y demográfico de la provincia.
} 
Figura 2. Estructura por edad y sexo de la población extranjera en la provincia de Alicante, 2002 y 2017.

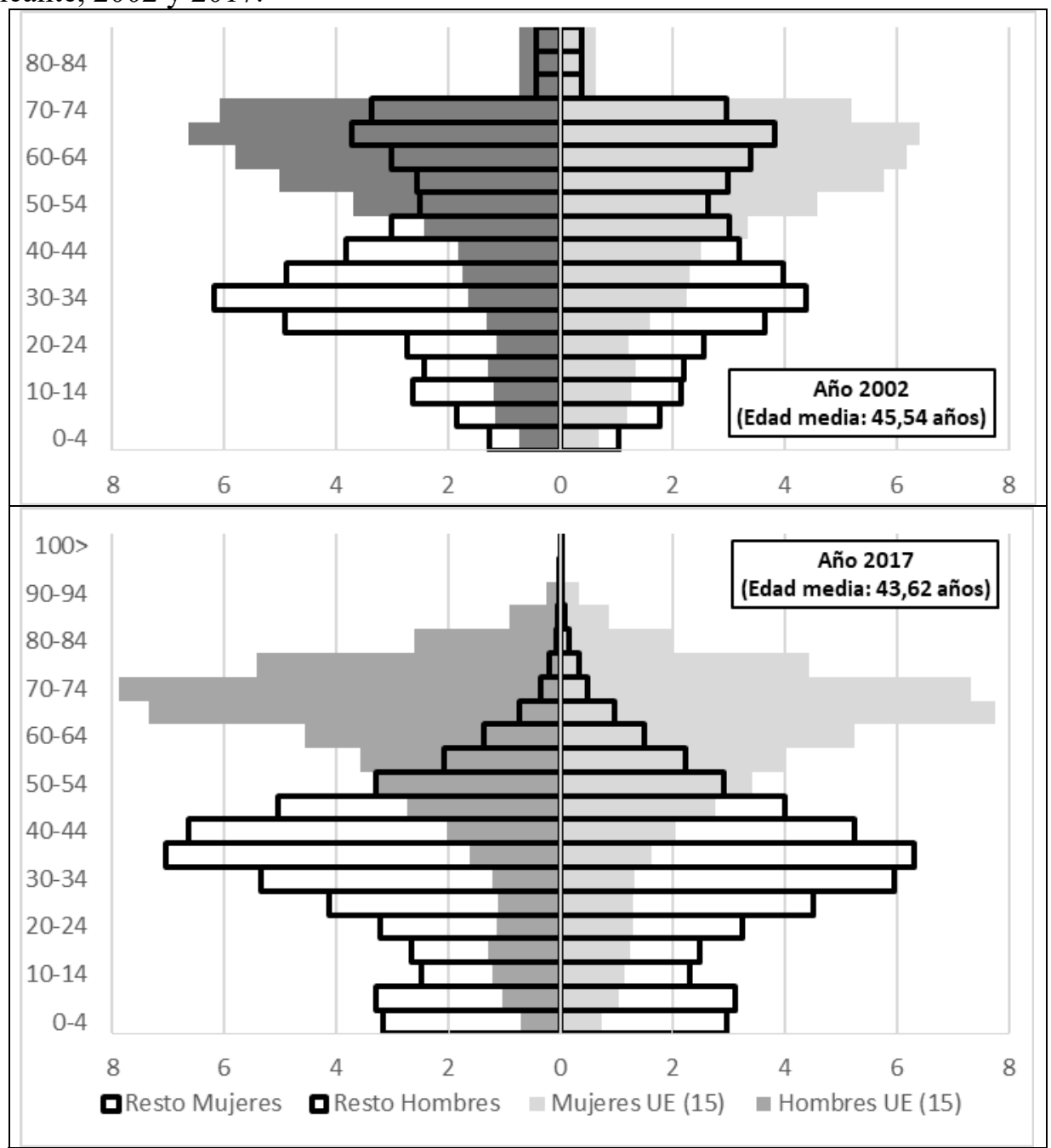

Fuente: IVE. Padrón municipal de habitantes a 1 de enero, 2002 y 2017. Elaboración propia. En UE 15 se incluye a Suiza y Noruega.

En esta línea, los cambios en la composición de los extranjeros en la Costa Blanca han operado en un doble sentido. En primer lugar, y si se considera el conjunto de la población extranjera se observa un reducido rejuvenecimiento en la composición por edades de esta población. Concretamente la estimación de la edad media en el año 2017 es de 43,62 años, cifra ligeramente inferior a la registrada, quince años atrás: 45,53 años. La reducción de residentes extranjeros originarios de destinos 
tradicionales centro- y norte-europeos, junto a una mayor diversificación de los lugares de procedencia, explican dicho comportamiento en relación a las estructuras demográficas por edades. Además, y como refuerzo a ese ligero rejuvenecimiento en la composición por edades, se puede observar un importante crecimiento de la población infantil y adulta de aquellas personas procedentes de países norteafricanos, de Europa oriental o de Latinoamérica, quienes también constituyen el grueso de la generación soporte en las edades potencialmente activas de esta población (figura 2). Ello refleja la persistencia de comunidades de extranjeros diferenciadas por unas edades más vinculadas al residencialismo y otras, además, a actividades económicas y formativas.

Sirviéndonos del ejemplo británico (mapa 1) se puede observar en algunos municipios del litoral cómo estos ciudadanos extranjeros representan una nacionalidad comunitaria que al final del periodo 2002-2017 cuenta con registros de crecimiento relativos muy bajos o incluso negativos, pese a ser en términos absolutos los que alcanzan las mayores concentraciones. Dicha situación contrasta con los registros de crecimiento acumulado observados en el interior noroccidental de la provincia que denotan cambios residenciales desde las zonas litorales hacia municipios interiores y de montaña (Cortés, Seguí, 2009). Por su parte, la evolución y distribución geográfica de las otras nacionalidades extranjeras más numerosas de la Costa Blanca: marroquí, rumana y rusa, presentan diferencias que permiten obtener una imagen de conjunto de los cambios operados en los últimos años. La población marroquí ha aumentado progresivamente su peso demográfico en la provincia con 38.106 residentes, si bien su distribución territorial difiere sustancialmente de los anteriores extranjeros al localizarse preferentemente en las principales ciudades provinciales: Alicante y Elche y en los municipios más agrícolas del sur lindantes con la Región de Murcia. Por su parte, los inmigrantes procedentes de Rumania han sido quienes han registrado las fluctuaciones más intensas durante el periodo considerado, pues durante los años 2002 y 2008 el número de residentes aumentó casi 15 veces más, para después descender como respuesta al creciente desempleo y aumento de precariedad durante la Gran Recesión (Viruela, 2016: 202). En cambio, su distribución es más homogénea entre las principales ciudades provinciales, especialmente en Alicante, Elche y Benidorm, y también en otros núcleos no turísticos del interior provincial. Por último, de los grupos de extranjeros más numerosos, los ciudadanos procedentes de Rusia constituyen la nacionalidad que en términos relativos más ha crecido durante los últimos cinco años. Por su distribución geográfica, los lugares de residencia se sitúan en los principales municipios turísticos de la provincia, mientras que en los padrones de los municipios del interior sus registros no son abultados. Representan una población no comunitaria que, tras varias experiencias como turistas en España opta por buscar una segunda residencia y empadronarse, particularmente en la Costa Blanca. Este fenómeno denota un cambio en los flujos migratorios observados en los últimos años y es un claro exponente de las transformaciones recientes de las migraciones internacionales con destino a 
España «Los rusos que optan por adquirir una vivienda en España eligen en dos de cada tres casos la provincia de Alicante» (Prokopenko, 2014: 382).

Mapa 1. Tasa de variación acumulada de las principales nacionalidades extranjeras 2002-2017. Valores absolutos 2017.

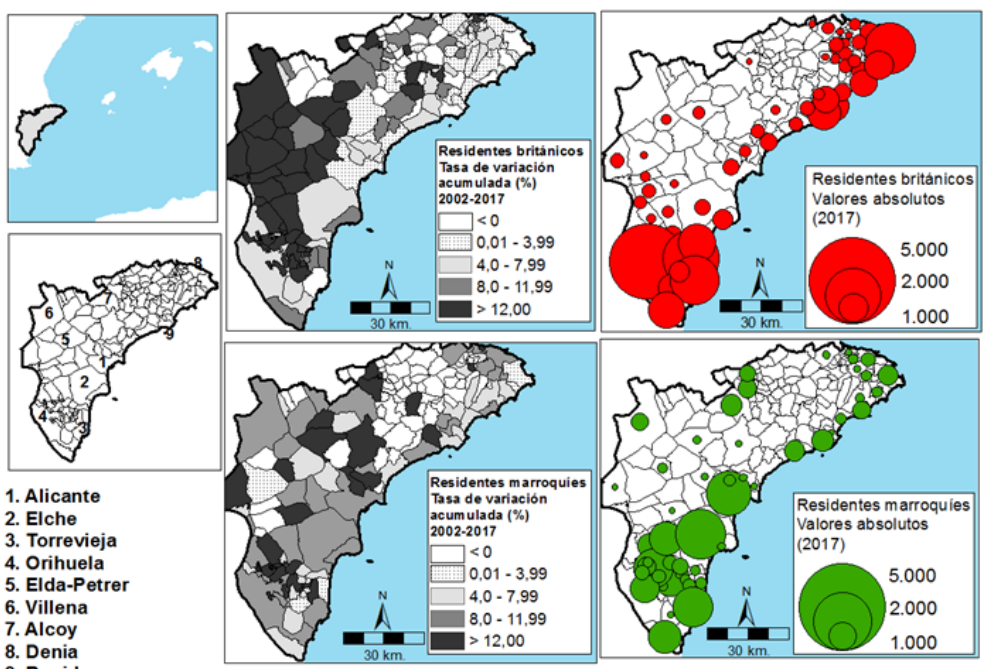

9. Benidorm

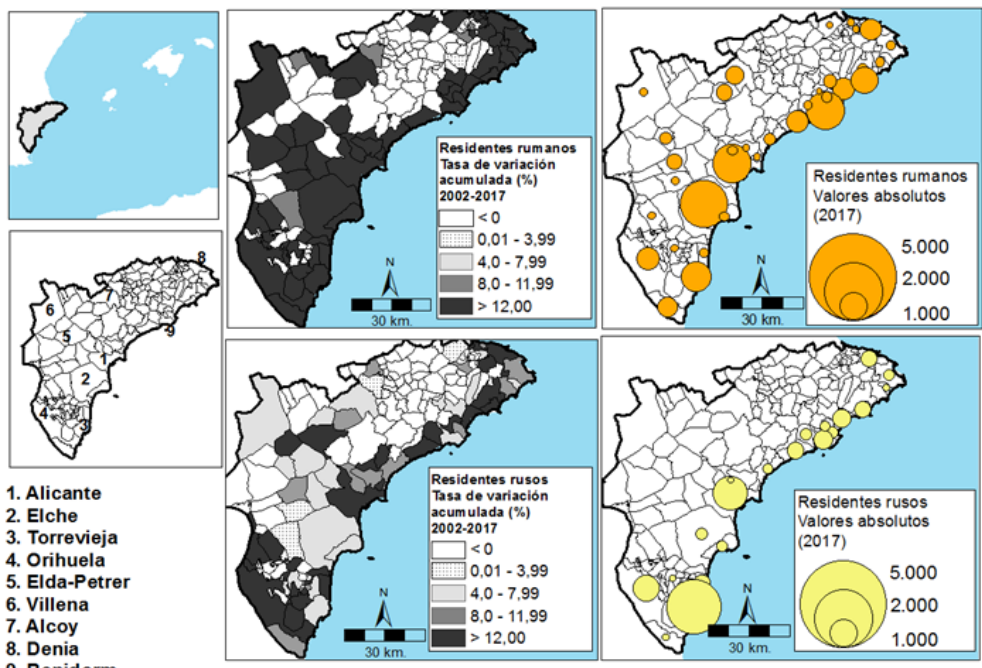

Fuente: Padrón municipal de habitantes a 1 de enero, 2002 y 2017. Elaboración propia. Para la representación de los valores absolutos sólo se considera los municipios con más de 100 habitantes empadronados. 
Mapa 2. Evolución e indicadores de localización de la población extranjera en la Costa Blanca.
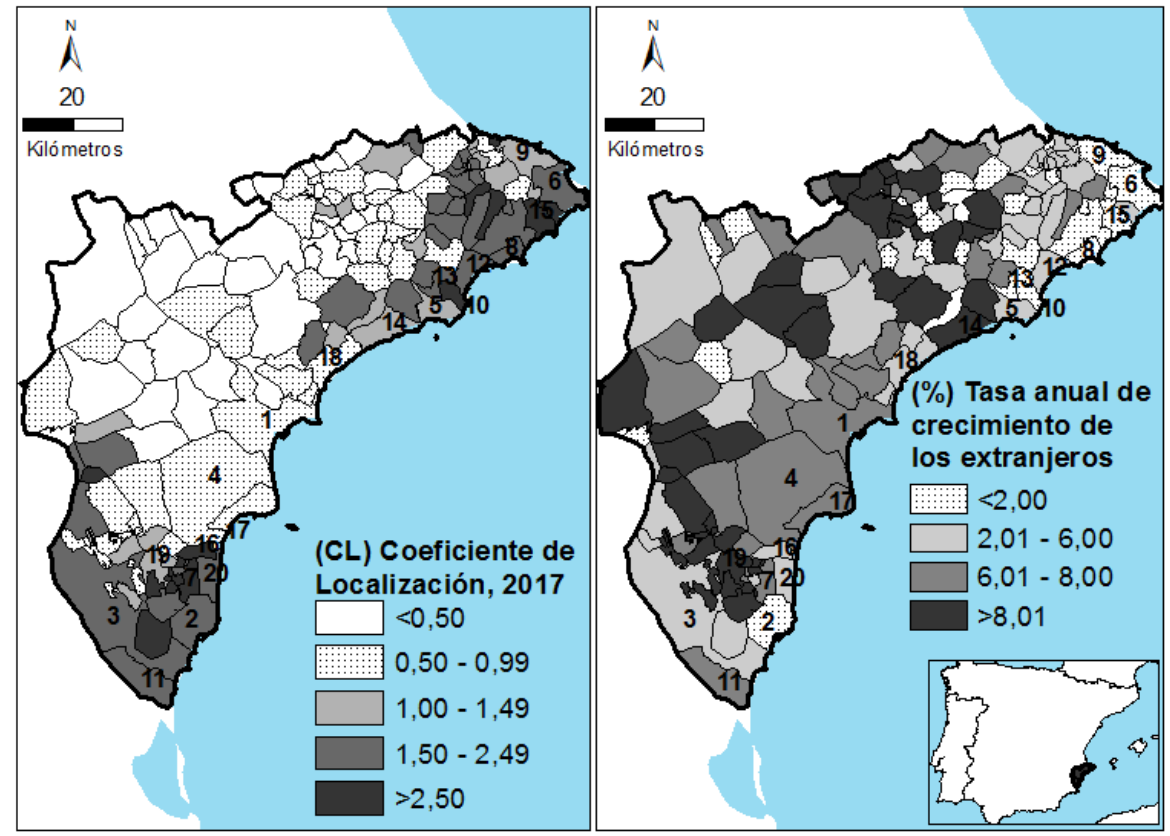

\begin{tabular}{|l|c|c|c|c|c|c|c|}
\hline & $\begin{array}{c}\text { Población } \\
\mathbf{2 0 0 2}\end{array}$ & $\begin{array}{c}\text { Población } \\
\mathbf{2 0 1 7}\end{array}$ & $\begin{array}{c}\text { C. acumulado } \\
\text { de la población } \\
\mathbf{0 2 - 1 7}\end{array}$ & $\begin{array}{c}\text { Extranje ros } \\
\mathbf{2 0 0 2}\end{array}$ & $\begin{array}{c}\text { Extranjeros } \\
\mathbf{2 0 1 7}\end{array}$ & $\begin{array}{c}\text { C. acumulado } \\
\text { extranjeros } \\
\mathbf{0 2 - 1 7}\end{array}$ & $\begin{array}{c}\text { extranjeros } \\
\text { /población } \\
\mathbf{2 0 1 7} \text { (\%) }\end{array}$ \\
\hline 1. Alicante & 293.629 & 329.988 & 0,78 & 15.907 & 40.123 & 6,36 & 12,16 \\
\hline 2. Torrevieja & 69.763 & 83.252 & 1,19 & 28.995 & 32.618 & 0,79 & 39,18 \\
\hline 3. Orihuela & 61.018 & 76.097 & 1,48 & 11.758 & 23.697 & 4,78 & 31,14 \\
\hline 4. Elche & 201.731 & 228.675 & 0,84 & 7.226 & 21.594 & 7,57 & 9,44 \\
\hline 5. Benidorm & 61.352 & 66.831 & 0,57 & 10.371 & 17.636 & 3,60 & 26,39 \\
\hline 6. Jávea & 26.368 & 27.060 & 0,17 & 12.988 & 11.353 & $-0,89$ & 41,95 \\
\hline 7. Rojales & 9.026 & 16.231 & 3,99 & 4.324 & 11.007 & 6,43 & 67,81 \\
\hline 8. Calpe & 20.103 & 20.804 & 0,23 & 10.298 & 9.154 & $-0,78$ & 44,00 \\
\hline 9. Denia & 34.686 & 41.568 & 1,21 & 6.856 & 8.781 & 1,66 & 21,12 \\
\hline 10. Alfàs del Pi & 15.848 & 18.394 & 1,00 & 8.638 & 8.540 & $-0,08$ & 46,43 \\
\hline 11. Pilar de la Horadada & 13.246 & 21.202 & 3,19 & 3.258 & 8.025 & 6,19 & 37,85 \\
\hline 12. Altea & 17.608 & 21.813 & 1,44 & 3.783 & 6.884 & 4,07 & 31,56 \\
\hline 13. La Nucia & 10.135 & 18.548 & 4,11 & 5.334 & 6.627 & 1,46 & 35,73 \\
\hline 14. Villajoyosa & 25.073 & 33.607 & 1,97 & 1.789 & 6.081 & 8,50 & 18,09 \\
\hline 15. Teulada & 10.858 & 10.097 & $-0,48$ & 6.247 & 4.948 & $-1,54$ & 49,00 \\
\hline 16. San Fulgencio & 4.815 & 7.646 & 3,13 & 2.395 & 4.752 & 4,67 & 62,15 \\
\hline 17. Santa Pola & 20.965 & 31.137 & 2,67 & 1.855 & 4.648 & 6,32 & 14,93 \\
\hline 18. El Campello & 20.393 & 27.604 & 2,04 & 2.528 & 4.486 & 3,90 & 16,25 \\
\hline 19. Almoradíl & 14.334 & 20.332 & 2,36 & 721 & 4.354 & 12,74 & 21,41 \\
\hline 20. Guardamar del Segura & 10.732 & 14.716 & 2,13 & 1.895 & 4.272 & 5,57 & 29,03 \\
\hline Provincia de Alicante & 1.557 .587 & 1.825 .443 & 1,06 & 185.535 & 325.120 & 3,81 & 17,81 \\
\hline
\end{tabular}

Fuente: IVE. Padrón municipal de habitantes a 1 de enero, 2002 y 2017. Elaboración propia. 
Atendiendo a las nacionalidades más representativas de extranjeros, los padrones de habitantes comienzan a reflejar que, en la Costa Blanca, aun manteniendo un atractivo en relación a las denominadas migraciones de retiro, el actual panorama sociodemográfico manifiesta una tendencia distinta a la de las últimas décadas; que pasa por una contracción de los migrantes procedentes de países de Europa central y del norte, y un relativo rejuvenecimiento de la composición de los extranjeros. Esta tendencia está impulsada por ciudadanos originarios del norte de África y de Europa oriental que sustituyen el dinamismo de los migrantes latinoamericanos, quienes desde inicios del año 2000 y hasta bien entrada esa década registraron aumentos absolutos muy notables, para luego descender de manera sostenida por arraigo (doble nacionalidad) o por re-emigración (figura 1).

Es por ello que una rápida descripción territorial de la dinámica de la población extranjera de los municipios que registran los mayores contingentes de población extranjera muestra, al menos, tres dinámicas destacables entre comienzos de siglo y la actualidad (mapa 2). En primer lugar, se observa que, salvo alguna excepción, son las principales ciudades de la Costa Blanca: Alicante y Elche, aquellas cuyas tasas acumuladas de crecimiento de población extranjera son mayores: $6,36 \%$ y 7,57, respectivamente. En segundo lugar, se aprecia que los municipios situados al sur de la provincia presentan aumentos muy notables de población extranjera, de tal manera que se pueden encontrar registros en municipios donde más de la mitad de su población proviene de fuera de España: Rojales $(67,81 \%)$ o San Fulgencio $(62,15 \%)$; se trata de un territorio en el que hay referentes consolidados de turismo vacacional como Torrevieja u Orihuela Costa. Y que se configura como el que cuenta con más población extranjera de toda la Costa Blanca. En tercer lugar, los municipios litorales y pre-litorales del norte de la provincia, salvo Villajoyosa y Altea, presentan unos incrementos de población extranjera inferiores a los de la media provincial, es el caso de Denia o la Nucía; o incluso pérdida de población extranjera: Teulada, Jávea, Calpe o Alfàs del Pi (mapa 2). En este ámbito particular son más evidentes los cambios demográficos de fin de ciclo migratorio de muchos de los residentes extranjeros más antiguos.

\section{Relación entre el precio de la vivienda y la localización de extranjeros}

Las tres dinámicas demográficas identificadas anteriormente representan la evolución más reciente de la población extranjera en litoral alicantino, y permiten encontrar paralelismos con la distribución media del precio por metro cuadrado por el que se ofertan las viviendas residenciales. No en vano, y a través del coeficiente de 
correlación de pearson ${ }^{6}$ se puede constatar estadísticamente que el coeficiente de localización de la población extranjera ${ }^{7}(\mathrm{CL})$ y el precio por metro cuadrado de vivienda (VMC) mantienen una correlación lineal significativa: $r=0.6808(p .<$ .0001). Lo cual permite presuponer que, en el conjunto de los municipios de la provincia de Alicante, a mayor concentración de población extranjera, los precios de la vivienda serán más elevados. A pesar de ello hay que matizar esta afirmación, pues a diferencia de lo que sucede en ámbitos metropolitanos o urbanos estudiados en otras investigaciones citadas en este trabajo, la existencia de determinadas nacionalidades extranjeras de carácter laboral presenta el efecto contrario. Cabe señalar en esta parte del análisis que se está considerando el conjunto de extranjeros, sin desglosar por nacionalidades ni por secciones censales (mapa 3). A ese respecto, otro aspecto no menos llamativo y que conviene resaltar es que a nivel provincial se puede identificar una ligera correlación negativa $(\mathrm{r}=-0.5212)$ entre aquellos municipios que han registrado bajas tasas de crecimiento anual acumulado de extranjeros $\mathrm{y}$, al mismo tiempo, disponen de un parque de viviendas en venta más barato; coincide precisamente con los municipios interiores y alejados del litoral. Este hecho contrasta con el mayor dinamismo inmobiliario y demográfico de la costa (mapas 2 y 3 ). Sin embargo, y en esta aproximación entre el precio de la vivienda y coeficiente de localización de los extranjeros, la recta de mínimos cuadrados nos muestra que la regresión lineal de ambas variables, la dependiente, es decir, la que se está midiendo $(\mathrm{y}=\mathrm{VMC})$ y la independiente, la que muestra sus efectos en la anterior $(\mathrm{x}=\mathrm{CL})$, presenta un coeficiente de determinación de $\mathrm{R} 2=0.3736$ (mapa 3). Es decir, se puede inferir que para los municipios de la Costa Blanca el $37 \%$ del precio medio por metro cuadrado de vivienda vendría explicado por la localización geográfica de los extranjeros. Es evidente que semejante afirmación debe ser de nuevo matizada, tanto por la escala geográfica empleada en el análisis como por el carácter multivariable y multifactorial de las pautas de localización residencial de la población extranjera; que sobrepasa el mero hecho del acceso económico a la vivienda y que requeriría introducir más variables independientes (y no sólo demográficas) en la regresión.

\footnotetext{
${ }^{6}$ El coeficiente de correlación de pearson, es un índice que mide la relación lineal de dos variables cuantitativas. Los valores próximos a -1 significan una correlación negativa, con valores cercanos a 0 no existe correlación y con valores próximos a 1 significa que la correlación es positiva.

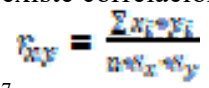

${ }^{7}$ El coeficiente de localización de extranjeros es un indicador que relaciona la proporción de un subgrupo de población (extranjeros o una nacionalidad concreta) en un determinado espacio con el valor de esa población para el conjunto territorial de referencia.
}

$c_{\tau_{\tau}}=\frac{\left(\frac{w}{\bar{T}}\right)}{\left(\frac{\tilde{R}}{\tau}\right)}$ 
Mapa 3. Distribución del precio medio de venta por metro cuadrado de vivienda residencial y regresión entre el precio por metro cuadrado de vivienda y el coeficiente de localización de la población extranjera, año 2017.

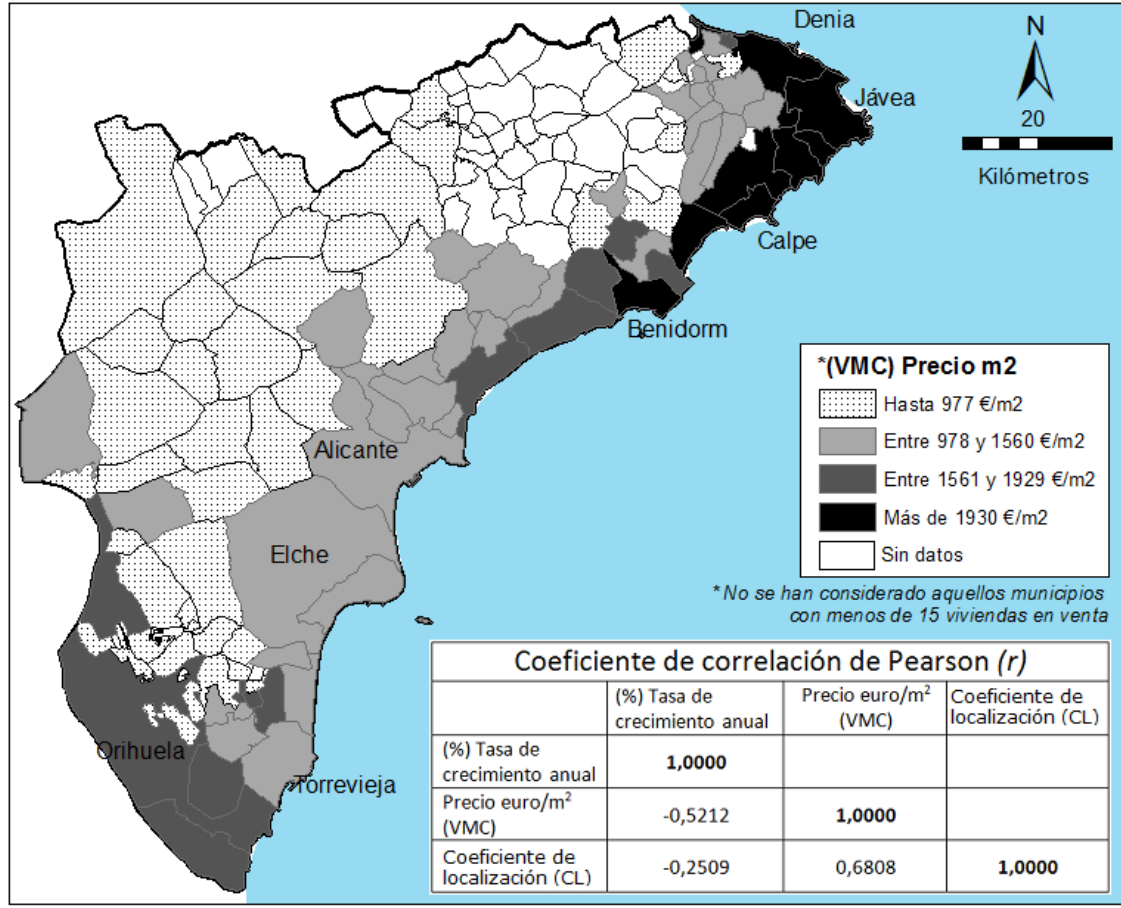

\section{Curva de regresión ajustada}

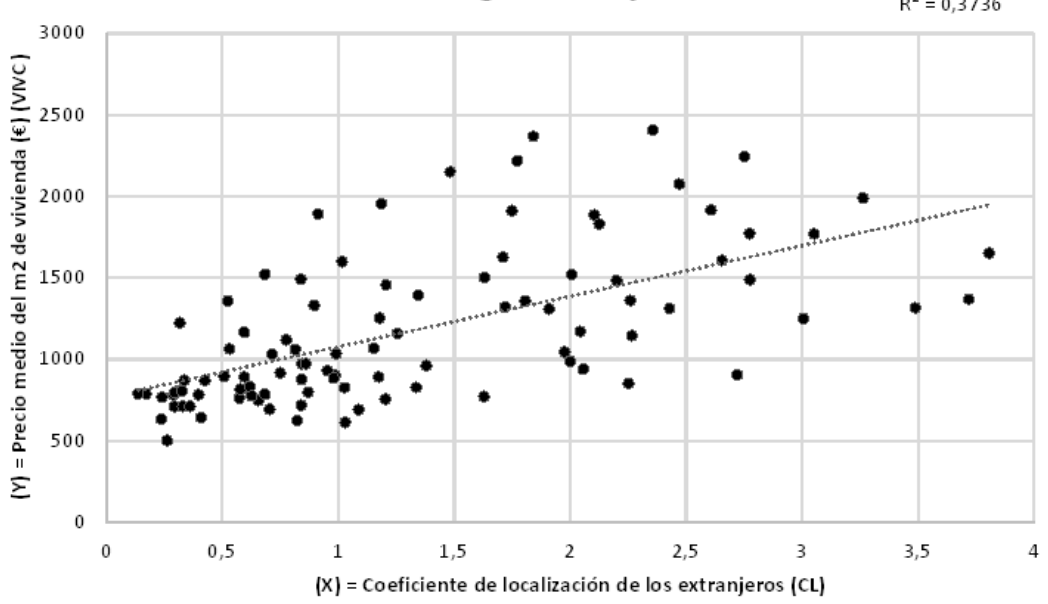

Fuente: Idealista. IVE, padrón municipal de habitantes, 2017. Elaboración propia. 
En consecuencia, son evidentes las enormes diferencias en la distribución del precio de la vivienda entre el interior y el litoral de la provincia, precisamente entre los lugares con menor y mayor concentración de la población extranjera. En el primero de los casos, apenas se distinguen municipios cuyas viviendas en venta registran valores de mercado superiores a $1.000 € / \mathrm{m}^{2}$, mientras que en la costa todos superan muy holgadamente dicho umbral, especialmente en aquellos municipios donde el turismo, sea vacacional o residencial, está más consolidado. Y, aunque no es objeto de esta investigación predecir estadísticamente los componentes principales, que mejor se ajustan al precio de la vivienda en estos destinos turísticos, esta aproximación nos permite enfocar el análisis a una escala de mayor detalle atendiendo al precio medio que en el mercado inmobiliario se paga por el metro cuadrado de vivienda en relación a la localización residencial de las nacionalidades más numerosas empadronadas en los enclaves litorales y pre-litorales de la Costa Blanca.

\section{Relación entre el precio de la vivienda y los lugares de residencia de la población extranjera a escala inframunicipal. Los ejemplos de torrevieja y Benidorm}

Partiendo de los anteriores resultados se puede observar una serie de características que permiten profundizar en la relación que se ha registrado para el conjunto de los municipios de la provincia de Alicante entre el precio medio de la vivienda y la presencia de población extranjera empadronada. Con ese propósito utilizamos como referentes de la Costa Blanca los casos de Torrevieja, como destino turístico de masas en el que la vertiente inmobiliaria ha sido dominante en sistema local (Vera-Rebollo; Ivars; Celdrán, 2016: 731), y el de Benidorm, como paradigma de ociurbe que se ha configurado como el principal destino turístico del mediterráneo español (Baños; Rico, 2016: 93). En efecto, desde comienzos de siglo, Torrevieja ha mantenido prácticamente invariable la proporción de extranjeros residentes en su término municipal en alrededor del $40 \%$ de su población total (mapa 2). Sin embargo, su composición ha variado sustancialmente. Si los ciudadanos británicos suponían el $25,5 \%$ de los extranjeros en 2002, en la actualidad sólo representan el 13,6\%, al haber pasado de 7.381 a 4.431 empadronados. En cambio, los ciudadanos procedentes de países de Europa del este (Rusia, Ucrania, Rumanía y Bulgaria) son aquellos que más han incrementado su presencia, siendo mayoritarios quienes provienen de Rusia: 4.884 (cuadro 2). 
Cuadro 2. Indicadores de población extranjera en Torrevieja.

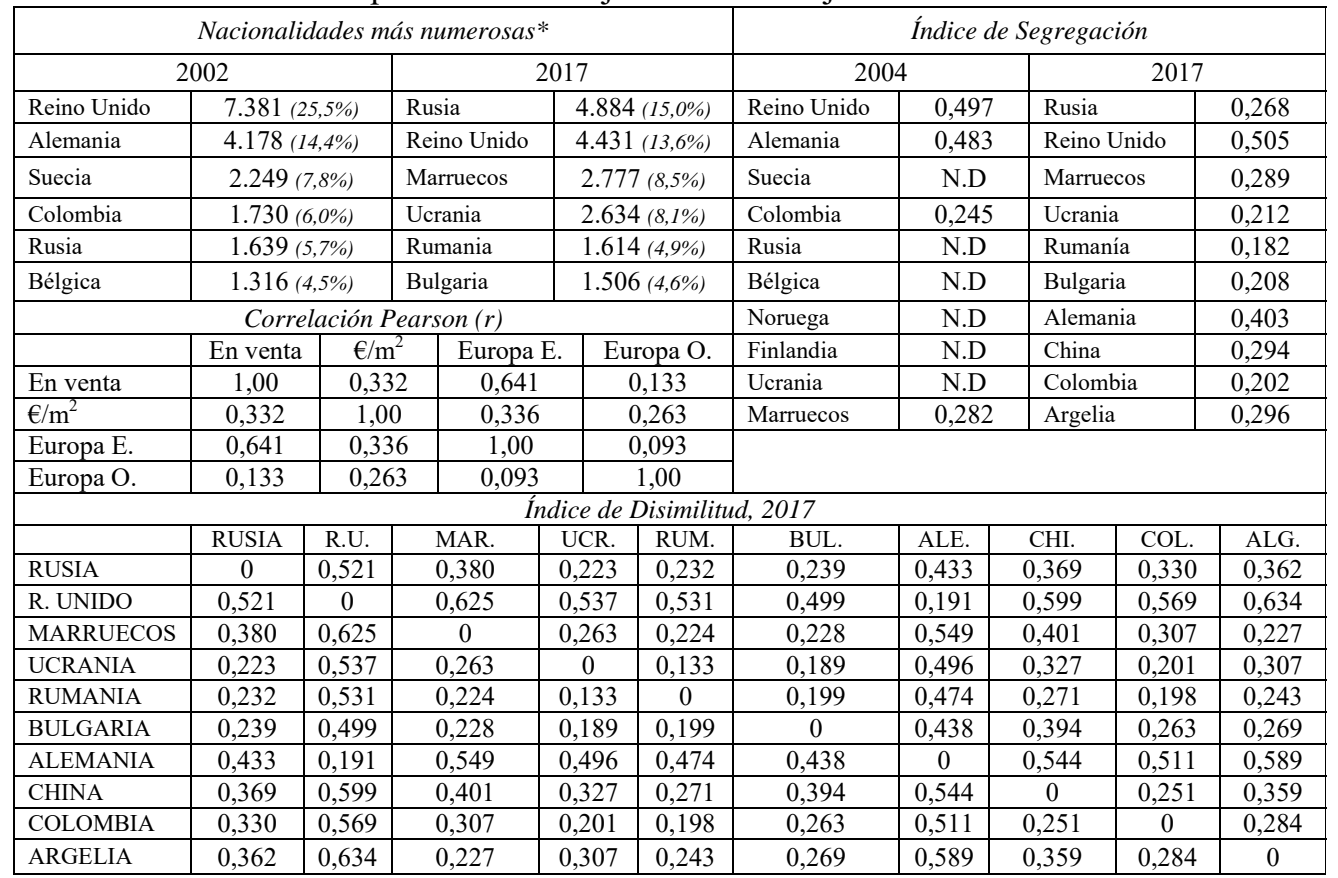

Fuente: Idealista. INE, padrón municipal de habitantes. Elaboración propia. *Entre paréntesis los valores relativos.

Si a escala de sección censal se confrontan los índices de segregación de los distintos colectivos nacionales para el año más antiguo de la serie con datos disponibles, se comprueba cómo estos presentan para los británicos una tendencia al alza: 0.497 en el año 2004 y 0.505 en 2017 , y que demuestra cómo este aumento de la segregación ${ }^{8}$ ha ido en paralelo a la reducción de efectivos absolutos de esta nacionalidad. En esta línea, los valores anteriores son perfectamente congruentes si se atiende a que en la actualidad el índice de disimilitud ${ }^{9}$ de las diez nacionalidades ${ }^{10}$

${ }^{8}$ El índice de segregación mide la distribución geográfica de un colectivo de población diferenciado por su nacionalidad o etnia, y proporciona un valor único para el conjunto del municipio. Los valores próximos a 1 significan que ese colectivo está segregado respecto al conjunto de la población municipal, y los valores cercanos a 0 muestran una distribución igualitaria.

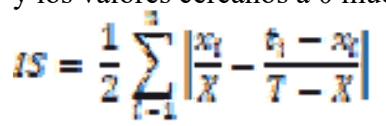

${ }^{9}$ El índice de disimilitud compara la proporción de miembros de un mismo colectivo nacional o étnico con respecto a otro colectivo para medir la uniformidad en una misma unidad de superficie. Los valores 
con mayor presencia en el municipio muestra por término general una uniformidad no significativa entre los residentes de distintas nacionalidades entre sí (cuadro 1). A excepción de los residentes británicos y alemanes quienes prácticamente alcanzan puntuaciones superiores a 0.500 con el resto de nacionalidades, menos entre ellos (0.191). Se trata de unos valores que hasta cierto punto reflejan un relativo aislamiento de ambas comunidades respecto al resto de residentes.

En esta línea, y a tenor de la confrontación de la información disponible, se puede constatar que no hay una relación directa y unívoca entre el precio de la vivienda y la presencia de diferentes colectivos de extranjeros en Torrevieja (cuadro 2). Una explicación de estos registros podría considerar que durante varios años una parte importante de la promoción residencial de viviendas ha estado dirigida a satisfacer la demanda internacional de una población tendente a la autoexclusión con una edad media próxima a la jubilación o directamente jubilada. Transcurridas varias décadas, y una vez consolidado el carácter residencial del municipio, los actuales flujos migratorios incorporan a dicha especialización residencial nuevos residentes cuyas expectativas de actividad laboral, recreativa o formativa trascienden la mera autoexclusión residencial. De ahí que sean más reducidos los citados indicadores de segregación entre estos nuevos inmigrantes y que tengan un reparto más uniforme en el municipio. Pese a que registra una ligera prevalencia por los espacios más centrales del núcleo urbano para los migrantes procedentes de Europa oriental y más periférico para quienes proceden de Reino Unido o Alemania (mapa 4).

Consdierando del precio medio de venta de las viviendas y de la agrupación de las nacionalidades extranjeras más numerosas en los dos grupos ya mencionados: los europeos occidentales (Reino Unido y Alemania) y los europeos orientales (Rusia, Ucrania, Rumanía y Bulgaria), el índice de correlación de pearson (r) muestra puntuaciones muy bajas para ambos cruces. Sin embargo, la situación cambia si se atiende únicamente al número de viviendas en venta al margen de su precio, pues sí que hay una relación bastante ajustada $(\mathrm{r}=0.641)$ entre la existencia de secciones censales con una abundante oferta de viviendas en venta y las elevadas proporciones de extranjeros procedentes de Europa oriental, que son precisamente quienes que más han aumentado su presencia en el municipio hasta ser los residentes más numerosos (cuadro 2).

próximos a 1 significan que ambos colectivos tienen un reparto poco uniforme, los valores cercanos a 0 muestran una distribución uniforme entre ambos colectivos.

$$
D D=\frac{1}{2} \sum_{i=1}^{n}\left|\frac{x_{i}}{R}-\frac{x_{i}-x}{x-y}\right|
$$

${ }^{10}$ Excepto ciudadanos suecos que en 2017 alcanzaban las 925 personas y constituían la novena nacionalidad con mayor presencia en el municipio, aunque no se dispone de su reparto por secciones censales. 
Mapa 4. Torrevieja, reparto del precio medio por metro cuadrado de vivienda y de la agrupación de las principales nacionalidades extranjeras, 2017
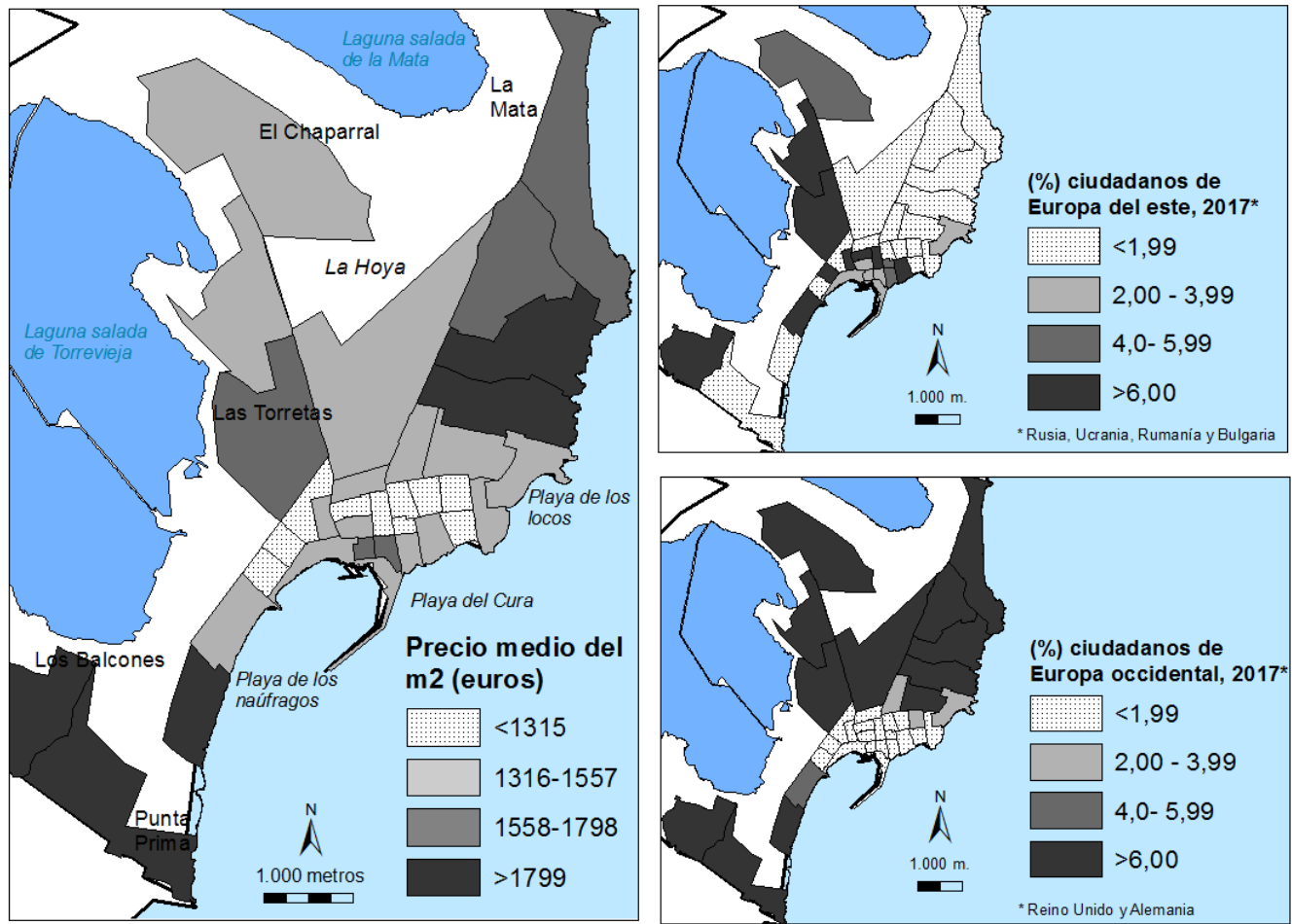

Fuente: Idealista. INE, padrón municipal de habitantes. Elaboración propia.

Estos resultados son suficientemente significativos para poder afirmar que el reparto geográfico de la población extranjera en Torrevieja se explica más por la disponibilidad y cantidad de viviendas en venta que por la presencia previa de conciudadanos de la misma nacionalidad. Sin olvidarnos que, en su conjunto, el municipio presenta un precio más bajo por metro cuadrado de vivienda que el registrado en los municipios de su entorno próximo: Orihuela, Rojales, San Fulgencio o Pilar de la Horadada. No conviene obviar que estos últimos municipios también pueden resultar más atractivos para extranjeros con motivaciones residenciales que quienes sólo residen por razones laborales o formativas. Esta afirmación se sostiene al afirmar que en estos municipios hay registradas tasas de crecimiento anual acumulado de extranjeros muy elevadas entre 2002 y $2017: 4,78 \%, 6,43 \%, 4,67 \%$ y $6,19 \%$, respectivamente, a diferencia de la alcanzada por Torrevieja para ese mismo periodo: 0,79\% (mapa 2). Estos hechos facilitan una distribución más variada entre los nuevos residentes extranjeros en Torrevieja que contrasta con la distribución más segregada que mantienen aquellos residentes foráneos cuya presencia es más antigua en el término municipal (mapa 4). 
Centrándonos en el caso de Benidorm, cabe advertir que la propia especialización del municipio en actividades turísticas y recreativas y ser un destino vacacional donde la demanda extranjera supera a la local (Obiol y Pitarch, 2011: 182) marca unas claras diferencias respecto a aquellos municipios más orientados al residencialismo, como sucede en el caso anterior.

El hecho de que en Benidorm más de una cuarta parte de su población empadronada sea extranjera $(26,4 \%)$ y que el residencialismo tenga un carácter secundario frente a las actividades turísticas y de servicios, contribuye a que pueda ser considerada como una "ciudad de paso", respecto a la permanencia o movilidad de la población extranjera, e incluso nacional. Es significativo que los índices segregación de las principales nacionalidades en Benidorm, aun moderados, son superiores a los registrados en el caso de Torrevieja, excepto para el caso de los ciudadanos británicos, quienes aun siendo los extranjeros más segregados de entre las diez nacionalidades más numerosas, su valor asciende a 0.479 , es decir, una cifra ligeramente inferior a la registrada por los británicos empadronados en Torrevieja. Aun así, los valores reflejan que la segregación de argelinos, rusos, pakistaníes y chinos no alcanzan los niveles anteriores, pero son los que más se aproximan (cuadro $3)$.

Atendiendo al índice de disimilitud, se observa cómo las puntuaciones obtenidas para una buena parte de las principales nacionalidades son altas, especialmente para las personas procedentes de Reino Unido, Pakistán o China, y en menor medida para extranjeros procedentes de Europa oriental (principalmente de Rumanía, Bulgaria o Ucrania). En situación análoga a lo que sucede en Torrevieja, se puede observar que existe una clara correlación lineal entre las mayores tasas de población extranjera y el mayor número de viviendas en venta $(\mathrm{r}=0.614)$. Esta relación es lo suficientemente relevante para considerar que, desde el punto de vista del acceso a la compra de una vivienda, Benidorm es un municipio bastante más atractivo que Torrevieja para invertir en bienes inmuebles. Basta comprobar que, para el conjunto del municipio, los precios de venta de las viviendas ofertadas son superiores a los de su entorno inmediato: Villajoyosa, Finestrat, la Nucía o Alfàs del Pi (mapa 3), lo que denota que Benidorm posee un atractivo que no sólo se explica desde el punto de vista residencial, ya que desde comienzos de los años 2000 sus registros acumulados de crecimiento de la población extranjera han sido superiores a los de buena parte de los municipios del litoral norte de la provincia Por otro lado, la mayor presencia de extranjeros no presenta puntuaciones elevadas con respecto al precio medio de la vivienda $(\mathrm{r}=0.331)$, esto permite descartar dicha presunción y desechar, al menos estadísticamente, que una mayor presencia de extranjeros supone la presencia de las viviendas con mayor precio de venta; si acaso habrá más extranjeros en esas secciones porque hay mayor disponibilidad habitacional. Este planteamiento lo ejemplifica la ligera correlación que se produce entre las secciones censales con un mayor número de viviendas en venta y el precio medio por metro cuadrado $(\mathrm{r}=0.5580)$, que no son las zonas que cuentan con las mayores proporciones de población extranjera, a excepción de las secciones censales situadas en primera y 
segunda línea de playa. En cuyo caso podemos encontrar dos excepciones: la Playa de Levante y el Rincón de Loix en donde sí coincide una mayor presencia de residentes extranjeros y el mayor precio por metro cuadro de vivienda residencial; y algunas zonas próximas al Parc de l'Aigüera y del centro urbano, en donde hay concentraciones de extranjeros (marroquíes y pakistaníes) en secciones urbanas con los precios más bajos de la vivienda (mapa 5).

Cuadro 3. Indicadores de población extranjera en Benidorm.

\begin{tabular}{|c|c|c|c|c|c|c|c|c|c|c|}
\hline \multicolumn{6}{|c|}{ Nacionalidades más numerosas* } & \multicolumn{5}{|c|}{ Índice de Segregación } \\
\hline \multicolumn{3}{|c|}{2002} & \multicolumn{3}{|c|}{2017} & \multicolumn{2}{|c|}{2004} & \multicolumn{3}{|c|}{2017} \\
\hline Reino Unido & \multicolumn{2}{|c|}{$2.346(22,6 \%)$} & Rumanía & \multicolumn{2}{|c|}{$2.486(14,1 \%)$} & Reino Unido & 0,433 & \multicolumn{2}{|c|}{ Rumanía } & 0,225 \\
\hline Países Bajos & \multicolumn{2}{|c|}{$723(7,0 \%)$} & Reino Unido & \multicolumn{2}{|c|}{$2.222(12,6 \%)$} & Países Bajos & N.D & \multicolumn{2}{|c|}{ Reino Unido } & 0,479 \\
\hline Colombia & \multicolumn{2}{|c|}{$712(6,9 \%)$} & Pakistán & \multicolumn{2}{|c|}{$1.548(8,8 \%)$} & Colombia & 0,198 & \multicolumn{2}{|l|}{ Pakistán } & 0,419 \\
\hline Bélgica & \multicolumn{2}{|c|}{$668(6,4 \%)$} & China & \multicolumn{2}{|c|}{$997(5,7 \%)$} & Bélgica & N.D & \multicolumn{2}{|l|}{ China } & 0,412 \\
\hline Ecuador & \multicolumn{2}{|c|}{$457(4,4 \%)$} & Marruecos & \multicolumn{2}{|c|}{$964(5,5 \%)$} & Ecuador & 0,263 & \multicolumn{2}{|c|}{ Marruecos } & 0,315 \\
\hline China & 435 & ,2\%) & Argelia & $905(5$, & & \multirow{2}{*}{$\begin{array}{l}\text { China } \\
\text { Argelia }\end{array}$} & N.D & \multicolumn{2}{|l|}{ Argelia } & 0,446 \\
\hline \multicolumn{6}{|c|}{ Correlación Pearson (r) } & & 0,243 & Bulgaria & & 0,286 \\
\hline & \multicolumn{2}{|c|}{ En venta } & $€ / \mathrm{m}^{2}$ & \multicolumn{2}{|c|}{ Extr. (\%) } & Francia & 0,363 & Rusia & & 0,423 \\
\hline En venta & & 00 & 0,558 & 0,61 & & Alemania & 0,425 & Ucrania & & 0,384 \\
\hline$€ / \mathrm{m}^{2}$ & & 58 & 1,00 & 0,33 & & Marruecos & 0,345 & Italia & & 0,281 \\
\hline Extr. (\%) & & 14 & 0,331 & 1,00 & & & & & & \\
\hline & & & & Índice de & Disim & ilitud, 2017 & & & & \\
\hline & RUM. & R.U. & PAKI. & CHIN. & MAI & ALG. & BUL. & RUSIA & UCR & ITALIA \\
\hline RUMANIA & 0 & 0,428 & 0,388 & 0,359 & 0,23 & 0,308 & 0,324 & 0,368 & 0,341 & 0,263 \\
\hline R. UNIDO & 0,428 & 0 & 0,636 & 0,470 & 0,51 & 0,437 & 0,511 & 0,529 & 0,537 & 0,445 \\
\hline PAKISTÁN & 0,388 & 0,636 & 0 & 0,556 & 0,36 & 0,526 & 0,471 & 0,591 & 0,491 & 0,518 \\
\hline CHINA & 0,359 & 0,470 & 0,556 & 0 & 0,37 & 0,329 & 0,482 & 0,490 & 0,509 & 0,348 \\
\hline MARRUE. & 0,234 & 0,510 & 0,365 & 0,376 & 0 & 0,345 & 0,344 & 0,465 & 0,378 & 0,379 \\
\hline ARGELIA & 0,308 & 0,437 & 0,526 & 0,329 & 0,34 & 0 & 0,514 & 0,367 & 0,397 & 0,388 \\
\hline BULGARIA & 0,324 & 0,511 & 0,471 & 0,482 & 0,34 & 0,514 & 0 & 0,426 & 0,315 & 0,315 \\
\hline RUSIA & 0,368 & 0,529 & 0,591 & 0,490 & 0,46 & 0,367 & 0,426 & 0 & 0,297 & 0,318 \\
\hline UCRANIA & 0,341 & 0,537 & 0,491 & 0,509 & 0,37 & 0,397 & 0,315 & 0,297 & 0 & 0,303 \\
\hline ITALIA & 0,263 & 0,445 & 0,518 & 0,348 & 0,37 & 0,388 & 0,315 & 0,318 & 0,303 & 0 \\
\hline
\end{tabular}

Fuente: Idealista. INE, padrón municipal de habitantes. Elaboración propia. *Entre paréntesis los valores relativos.

Ello nos lleva a presuponer que el nivel de segregación de esta población puede resultar algo mayor al comienzo del ciclo migratorio hasta que se produce un paulatino arraigo, lo que puede implicar la adquisición de comportamientos demográficos y patrones de localización en la ciudad más propios de aquellos residentes que más tiempo llevan en el lugar.

Pese a que en el conjunto de los municipios de la Costa Blanca se puede observar una cierta relación entre el precio medio de la vivienda y la presencia de población extranjera, dicha relación queda más matizada cuando el estudio se realiza a menor escala de análisis, especialmente en los municipios turísticos seleccionados. 
Mapa 5. Benidorm, reparto del precio medio por metro cuadrado de vivienda y de la proporción de la poblacion extranjera, 2017.
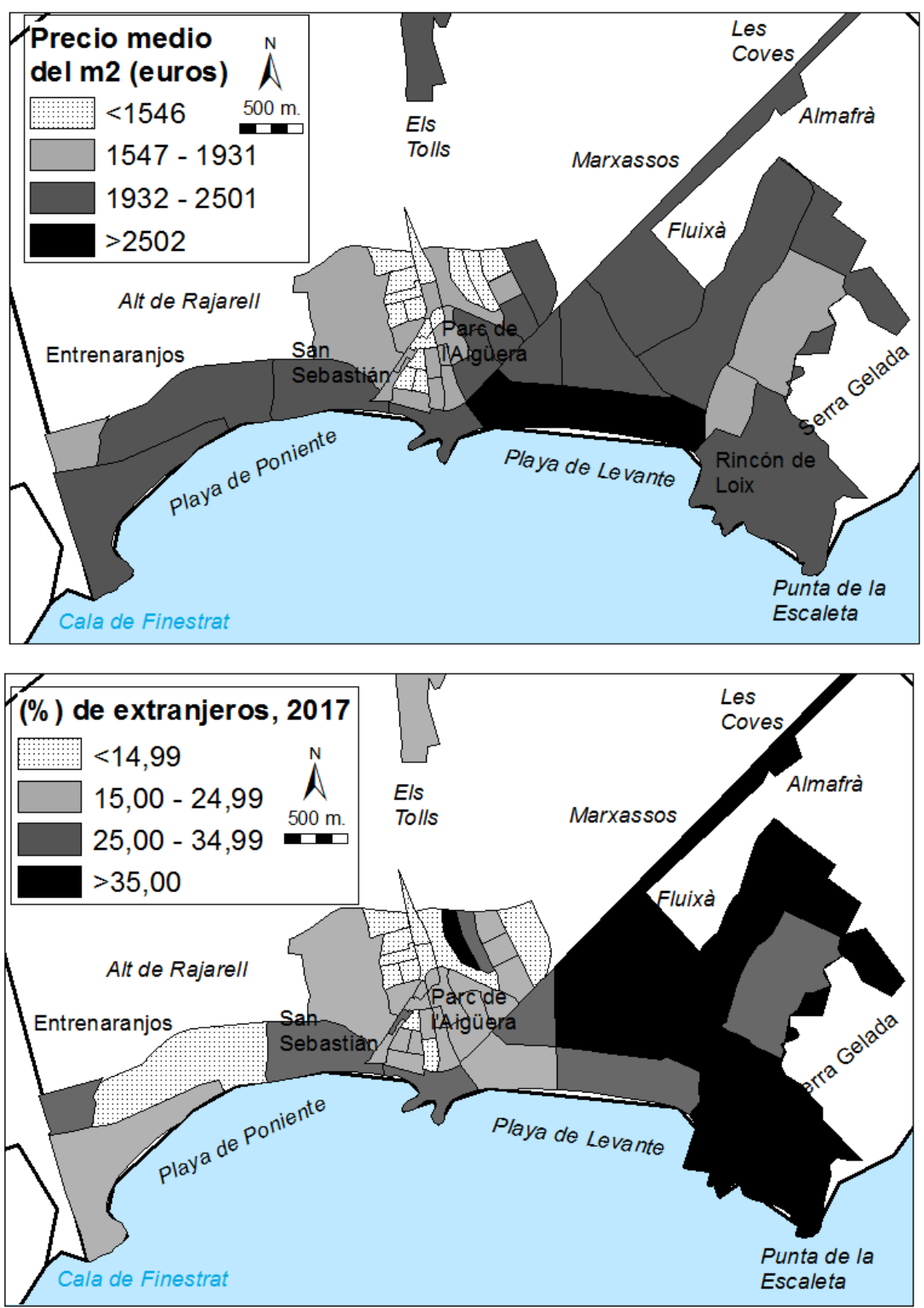

Fuente: Idealista. IVE, padrón municipal de habitantes. Elaboración propia. 
En efecto, disponer de manera desagregada información acerca de la composición y distribución de los extranjeros y de la cantidad de viviendas en venta y de su precio medio permite refutar aquellas especulaciones que sostienen que a mayor cantidad de extranjeros los precios de venta de los inmuebles serán mayores. Otra cuestión sería considerar dicho comportamiento residencial cuando se analiza dicha relación en determinadas urbanizaciones aisladas, levantadas al calor de la burbuja inmobiliaria y más alejadas de los núcleos urbanos. Se trataría en bastantes casos de enclaves de segregación voluntaria que originariamente estaban dirigidos a satisfacer la demanda de una población europea retirada. Población retirada que en menos de una década ha perdido peso demográfico frente a otras nacionalidades de Europa oriental, norte de África y América Latina, cuyo reparto geográfico, además de ser menos fragmentado y más central, obedece a otros factores que los meramente asociados a las migraciones de retiro.

\section{Conclusiones}

En las últimas décadas el ciclo migratorio de los extranjeros empadronados en los municipios de la Costa Blanca refleja cambios en las composiciones demográficas, en su distribución geográfica y en las expectativas que se generaron al calor del desarrollo de modelos residenciales dispersos. El crecimiento de las migraciones de retiro y la llegada de trabajadores latinoamericanos hasta finales de la primera década del siglo, dieron paso a la llegada de poblaciones procedentes de países con los que hasta entonces la migración residencial y laboral eran relativamente bajas: países magrebíes y de Europa oriental.

Dos de los efectos que se han comprobado son, en primer lugar, un ligero rejuvenecimiento de la edad media del conjunto de los extranjeros empadronados; y, en segundo lugar, una mayor concentración de extranjeros en los municipios litorales y pre-litorales de la provincia. Dicha litoralización de la población extranjera en el conjunto de la provincia se produce en paralelo a la consolidación de los municipios litorales como los lugares con mayor precio por metro cuadrado de las viviendas, de tal modo que a escala provincial existe un principio de relación significativo entre ambas variables. Sin embargo, al descender en la escala de análisis, se observa para los ejemplos de Torrevieja y Benidorm que dicha asociación pierde capacidad predictiva, pues los indicadores de segregación no son tan acusados como cabría prever, salvo las excepciones del Reino Unido y de otras nacionalidades cuya presencia es más antigua en la Costa Blanca. Especialmente esto es así en el caso torrevejense, cuyo modelo residencial está muy consolidado y en donde se ha observado un cambio en la composición de los extranjeros con una disimilitud muy reducida entre las principales nacionalidades; excepto con ciudadanos británicos y alemanes, quienes además han visto menguar su presencia en los años más recientes. En este caso el precio medio de la vivienda no es un factor explicativo de la localización residencial, especialmente de aquellos extranjeros que proceden de países de Europa oriental o del norte de África, pues estos se reparten de una manera 
más homogénea por el término municipal, tal y como atestiguan los índices de segregación. Por su parte la menor proporción de ciudadanos extranjeros residentes en Benidorm denota que, además de tener indicadores de segregación más altos, también se puede diferenciar mayor disimilitud entre las principales nacionalidades de extranjeros. La mayor presión inmobiliaria y la menor oferta de viviendas residenciales en este municipio justifica, en parte, esa mayor segregación entre inmigrantes retirados (británicos) e inmigrantes laborales (pakistaníes o marroquíes).

Salvo las citadas excepciones, la actual diferenciación residencial de los nuevos residentes extranjeros en los municipios estudiados no está tan vinculada con el precio de venta de las viviendas, ni con el lugar de procedencia de los extranjeros, sino con la existencia de secciones censales con un mayor número de inmuebles a la venta. De ahí que sean las secciones censales con mayor proporción de extranjeros aquellas que registran una relación más directa con la mayor oferta de viviendas: en Torrevieja para los europeos procedentes de Europa oriental $(\mathrm{r}=0,641)$, y en Benidorm para todos los extranjeros $(\mathrm{r}=0,614)$. Por tanto, el análisis presentado a través de estos dos municipios turísticos no permite inferir una relación que permita predecir causalidad entre el precio de la vivienda o la mayor o menor presencia de extranjeros. Sin embargo, para determinadas comunidades de extranjeros procedentes de países de renta alta y con una presencia más antigua en las ciudades sí se puede aceptar una mayor diferenciación residencial que se mantiene durante los años contemplados; aunque se trata de unos ciudadanos que, por otra parte, han visto menguado su peso absoluto y relativo.

Finalmente, con los datos disponibles, y en ausencia de otros indicadores cuantitativos fiables y actualizados que complementen el análisis, se evidencia la dificultad de encontrar patrones explicativos unívocos sobre la segregación residencial en emplazamientos urbano/turísticos sometidos a fuertes intereses que trascienden lo meramente geográfico. Además, procesos como el Brexit, la proliferación de apartamentos turísticos ofertados a través de plataformas de Internet, el acceso al alquiler de larga estancia para trabajadores en los municipios con mayor afluencia turística, el repunte que se observa en los precios de los inmuebles, las décadas de impactos ambientales o paisajísticos, las nuevas movilidades interiores o la eficacia de las estrategias municipales y autonómicas de ordenación del territorio pueden condicionar sin duda los lugares de residencia o de trabajo de la población, a pesar de la capacidad de atracción que mantiene la Costa Blanca. Por este motivo el estudio de esta nueva composición de la población extranjera requiere de enfoques que puedan reformular, a través de métodos de análisis cualitativo, la integración de los distintos colectivos de población en un territorio cuyas estructuras y dinámicas demográficas se han tornado más complejas en poco tiempo. Se trata de un territorio donde las migraciones de las últimas décadas contribuyen a generar un entorno socioterritorial en el que se han podido observar procesos de cambio ligados a subregistros de población, retorno de extranjeros a sus países de origen y la constante llegada de nuevos residentes extranjeros que han modificado la composición demográfica municipal en menos de quince años. 


\section{Bibliografía}

Amat, X. (2017): El mapa residencial inconcluso del litoral alicantino. En Sempere, J.D.; Cutillas, E. (ed.): La población en España. 40 años de cambio (1975-2015). Alicante, Publicacions de la Universitat d'Alacant, 345-362.

Arbaci, S., (2008): Hacia la construcción de un discurso sobre la inmigración en las ciudades del sur de Europa. La política urbanística y de vivienda como mecanismos estructurales de marginación étnica residencial. ACE: Architecture, City and Environment, 8 (3), 11-38. http://hdl.handle.net/2099/6571

Apparicio; P.; Martori, J.C.; Pearson, A.L.; Fournier, É.; Apparicio, D. (2014): An opensource software for calculating indices of urban residential segregation. Social Science Computer Review, 32 (1), 117-128. https://doi.org/10.1177/0894439313504539

Bayona, J.; López, A. (2011): Concentración, segregación y movilidad residencial de los extranjeros en Barcelona. Documents d'Anàlisi Geogràfica, 57 (3), 381-412. https://doi.org/10.5565/rev/dag.234

Baños, C.J.; Rico, E. (2016): La complementariedad litoral-interior en el marco de la renovación de destinos turísticos consolidados: el excursionismo organizado como elemento de relación. Cuadernos de Turismo, 38, 87-114. http://dx.doi.org/10.6018/turismo.38.271361

Batista, A.E.; Natera, J.J. (2013): Extranjeros en la Costa del Sol Occidental: diferenciación residencial y caracterización de su distribución espacial. Cuadernos Geográficos, 52, 264287. https://doi.org/10.30827/cuadgeo.v52i1.934

Batista, A.E.; Natera, J.J. (2018): La diferenciación residencial reciente en el municipio de Málaga. Una aplicación del Índice de Theil. Anales de Geografía de la Universidad Complutense, 38 (2), 289-311. http://dx.doi.org/10.5209/AGUC. 62481

Blazquez-Salom, M.; Artigues, A.A.; Yrigoy, I. (2015): Crisis y planificación turística neoliberal en las Islas Baleares. Investigaciones Turísticas, 9, 24-49. https://doi.org/10.14198/INTURI2015.9.02

Burriel, E. (2008). La década prodigiosa del urbanismo español (1997-2006). Scripta Nova. Revista electrónica de Geografía y Ciencias Sociales, 270. http://www.ub.edu/geocrit/sn/sn-270/sn-270-64.htm

Burriel, E. (2015): El estallido de la burbuja inmobiliaria y sus efectos en el territorio. En Albertos, J.M.; Sánchez, J.L. (coord.): Geografía de la crisis económica en España. Valencia, Servei de Publicacions de la Universitat de València, 101-140.

Cànoves, G.; Prat, J.M.; Blanco, A. (2016): Turismo en España, más allá del sol y la playa. Evolución reciente y cambios en los destinos de litoral hacia un turismo cultural. Boletín de la Asociación de Geógrafos Españoles, 71, 431-454. https://doi.org/10.21138/bage.2289

Capel, H. (1997): Los inmigrantes en la ciudad. Crecimiento económico, innovación y conflicto social. Scripta Nova: Revista electrónica de geografía y ciencias sociales, 3 (1). http://www.ub.edu/geocrit/sn-3.htm

Cortés, C.; Espinosa, A. (2009): Cambio de residencia desde las zonas litorales hacia los municipios rurales de la montaña de Alicante. Motivaciones y condiciones de la población jubilada europea. En López, L.; Abellán, A.; Godenau, D. (Coord.): Despoblación, 
envejecimiento y territorio: un análisis sobre la población española. León, Universidad de León, 137-148.

Díaz, R.; Parreño, J.M.; Domínguez, J. (2017): La vivienda secundaria y vacacional en la diversificación de la oferta alojativa de Canarias. Revista Atlántida, 8, 243-264.

Díaz, I. (2010): Distribución y segregación de la población residente extranjera en el municipio de Sevilla (2000-2008). Estudios Geográficos, 268, 103-128. https://doi.org/10.3989/estgeogr.0470/

Domínguez, L.; Martí, P.; Nolasco-Cirugeda, A. (2016): Turismo residencial de extranjeros en la Costa Blanca: su manifestación territorial y estudio de casos representativos. Scripta Nova: Revista electrónica de geografía y ciencias sociales, 547. http://www.ub.edu/geocrit/nova20.htm

Donat, C. (2012): La incidencia de las dinámicas demográficas en las necesidades residenciales y en la oferta de vivienda de la Región Metropolitana de Barcelona. Ciudad y territorio: Estudios territoriales, 174, 689-706.

García, A.; Jiménez, B.C. (2016): Envejecimiento y urbanización: implicaciones de dos procesos coincidentes. Investigaciones Geográficas, Boletín del Instituto de Geografía, UNAM, 89, 58-73. http://dx.doi.org/10.14350/rig.47362

González, M.J.; de Lazaro, M.L. (2012): La distribución espacial de la población inmigrante en dos ciudades medias: Alcalá de Henares y León y su relación con los precios de la vivienda. Anales de Geografía de la Universidad Complutense, 32 (2), 275-295. http://dx.doi.org/10.5209/rev_AGUC.2012.v32.n2.39721

González, F. (2008): El papel de los destinos turísticos en la transformación sociodemográfica del litoral mediterráneo español. Boletín de la Asociación de Geógrafos Españoles, 47, 79107.

Huete, R. (2008): Tendencias del turismo residencial. El caso del mediterráneo español. El periplo sustentable: revista de turismo, desarrollo y competitividad, núm 14.

Huete, R.; Mantecón, A.; Estévez, J. (2013): Challenges in Lifestyle Migration Research: Reflections and Findings about the Spanish Crisis. Mobilities, 8 (3), 331-348. https://doi.org/10.1080/17450101.2013.814236

Huete, R.; Mantecón, A. (2011): Más allá del turismo: movilidad residencial europea y nuevos núcleos urbanos. Boletín de la Asociación de Geógrafos Españoles, 56, 111-128.

La Parra, D.; Mateo, M.A. (2008): Health status and access to health care of British nationals living on the Costa Blanca, Spain. Ageing \& Society, 28, 85-102.

Mantecón, A. (2017): El turismo residencial no existe. Revisión de un concepto y crítica de su función ideológica. Cuadernos de Turismo, 40, 405-422. http://dx.doi.org/10.6018/turismo.40.310041

Mantecón, A.; Huete, R.; Mazón, T. (2009): Las urbanizaciones "europeas". Una investigación sobre las nuevas sociedades duales en el Mediterráneo. Scripta Nova: Revista electrónica de geografía y ciencias sociales, 301.

Mantecón, A.; Huete, R.; Membrado, J. C. (2016): Fragmentación socio-espacial, inmigración europea y discursos políticos en la provincia de Alicante. Boletín de la Asociación de Geógrafos Españoles, 72, 67-90. http://dx.doi.org/10.21138/bage.2332 
Mahleiros, J. (2002): Ethni-Cities: Residential Patterns in the Northern European and Mediterranean Metropolises-Implications for Policy Design. International journal of population geography, 8, 107-134.

Martí, P.; Nolasco-Cirugeda, A.; Serrano-Estrada, L. (2018). Estrategias de ocupación territorial en áreas turísticas consolidadas de la Costa Blanca (España). Boletín de la Asociación de Geógrafos Españoles, 76, 430-454. http://dx.doi.org/10.21138/bage.2529

Massey, D. S.; Denton, N.A. (1988): The Dimensions of Residential Segregation, Social Forces, 67 (2), 281-315.

Membrado, J.C. (2015): Migración residencial y urbanismo expansivo en el mediterráneo español. Cuadernos de Turismo, 35, 259-285. http://dx.doi.org/10.6018/turismo.35.221611

Módenes, J.A.; Bayona, J.; López-Colás (2013): Immigration and residential change in Spain. Population, space and place, 19, 294-310. https://doi.org/10.1002/psp.1712

Módenes, J.A.; López-Colas, J. (2014): Cambio demográfico reciente y vivienda en España: ¿hacia un nuevo sistema residencial? Revista Española de Investigaciones Sociológicas, 148, 103-134. https://doi.org/10.5477/cis/reis.148.103

Morote, A.F. (2014): Tipologías urbano-residenciales del litoral de Alicante: repercusiones territoriales. Ciudad y Territorio: Estudios Territoriales, n. 181, 431-443.

Morote, A.F.; Hernández, M. (2016): Población extranjera y turismo residencial en el litoral de Alicante (1969-2011): repercusiones territoriales. EURE, 126, 55-76.

Musterd, S.; Ostendorf, W.; Breebaart, M. (1997): Segregation in European Cities: Patterns and Policies. Tijdschrift voor Economische en Sociale Geografie, 88 (2), 182-187.

Musterd, S. (2011): The impact of immigrant's segregation and concentration on social integration in selected European contexts. Documents d'Anàlisi Geogràfica, 51 (3), 359380. https://doi.org/10.5565/rev/dag.226

Natera, J.J. (2015): Más dispersos pero más excluidos. Análisis de la evolución de la diferenciación y exclusión residenciales de los inmigrantes económicos en Andalucía. Estudios Geográficos, 279, 609-632. https://doi.org/10.3989/estgeogr.201522

Obiol, E. M.; Pitarch, M.D. (2011): El litoral turístico valenciano. Intereses y controversias en un territorio tensionado por el residencialismo. Boletín de la Asociación de Geógrafos Españoles, 56, 177-200.

Palacios, A.J. (2008): Fuentes estadísticas sobre la vivienda en España: un obstáculo para el diseño de la política de vivienda. Scriptanova, Vol. XII. Núm. 270

Palacios, A.J.; Vidal, M.J. (2014): La distribución intraurbana de los inmigrantes en las ciudades españolas: un análisis de casos con SIG y técnicas cuantitativas. Cuadernos Geográficos, 53 (1), 98-121. http://hdl.handle.net/10486/669571

Pareja-Eastway, M. (2009): The effects of the spanish housing system on the settlement patterns of immigrants. Tijdschrift voor Economische en Sociale Geografie, Vol. 100, No. 4, 519-534. https://doi.org/10.1111/j.1467-9663.2009.00556.x

Parreño, J.M.; Domínguez, J. (2008): Extranjería y diferenciación residencial en canarias: la perspectiva del microanálisis espacial. Investigaciones Geográficas, 45, 163-199.

Prokopenko, Y. (2014): Evolución del flujo turístico ruso y su importancia económica: el caso de la Costa Blanca. (Tesis Doctoral). Universidad de Alicante. 
Pujol-Perdices, M.; Gutiérrez, A. (2017): Segregación residencial de la población extranjera en un destino turístico maduro: el caso de La Pineda (Costa Dorada). Lurralde: Investigación y espacio, 40, 167-192.

Recaño, Joaquín y Jáuregui-Díaz, José Antonio (2014). "Emigración exterior y retorno de latinoamericanos desde España: una visión desde las dos orillas (2002-2012)". Notas de Población, 99, 177-240.

Rodes, J.; Rodríguez, V. (2018): Migrantes de retiro en España: estilos de vida multilocales y patrones de integración. Migraciones Internacionales, 34, 193-222. http://dx.doi.org/10.17428/rmi.v9i34.422

Romaní, J.; Casado-Díaz, J.M.; Lillo-Bañuls, A. (2017): Explorando las relaciones entre el desplazamiento al trabajo y los cambios de residencia en España. Un análisis con datos individuales. Papers, 102 (4), 705-725. http://dx.doi.org/10.5565/rev/papers. 2417

Roquer, S.; Alberich, J.; Muro, J.I. (2013): Segregación residencial de la población extranjera en ciudades medias de la Cataluña no metropolitana. En Valenzuela, M. (coord.): Las ciudades españolas en la encrucijada: entre el 'boom' inmobiliario y la crisis económica. Madrid, Asociación de Geógrafos Españoles, 335- 385.

Rovira, M.T.; Antón-Clavé, S. (2014): De destino a ciudad. La reformulación urbana de los destinos turísticos costeros maduros. El caso de la Costa Daurada central. Arquitectura, Ciudad y Entorno, 9 (25), 373-392. http://dx.doi.org/10.5821/ace.9.25.3632

Sabater, A.; Galeano, J.; Domingo, A. (2013): La transformación de las comunidades mayoritarias y la formación y evolución de los enclaves étnicos residenciales en España. Migraciones, 34, 11-44.

Salvà-Tomàs, P.A. (2011): El turismo residencial ¿una manifestación de nuevos turismos y nuevos comportamientos turísticos en el siglo XXI? Cuadernos de Turismo, 27, 823-836.

Vera, J.F.; Baños, C.J. (2010): renovación y reestructuración de los destinos turísticos consolidados del litoral: las prácticas recreativas en la evolución del espacio turístico. Boletín de la Asociación de Geógrafos Españoles, 53, 329-353.

Vera, J.F.; Ivars, J.; Celdrán, M.A. (2016): Evolución y metabolismo de un lugar transformado por el turismo de masas. Una interpretación del modelo turístico de Torrevieja desde la teoría de la dependencia de la trayectoria (path dependence). En Paisaje, cultura territorial y vivencia de la geografía: libro homenaje al profesor Alfredo Morales. Alicante, Universidad de Alicante, 705-738.

Vera, J.F.; Díez, D. (2016): Espacios y destinos turísticos. Canelobre, 66, 85-97.

Viruela, R. (2016): La movilidad geográfica de búlgaros y rumanos durante la Gran Recesión en España. Documents d'Anàlisi Geogràfica, 62/1, 183-206. https://doi.org/10.5565/rev/dag.237

Wissink, B.; Schwanen, R. van Kempen, R. (2016): Beyond residential segregation. Cities, 59, 126-130. https://doi.org/10.1016/j.cities.2016.08.010

Yrigoy, I. (2017): Airbnb en Menorca: ¿una nueva forma de gentrificación turística? Localización de la vivienda turística, agentes e impactos sobre el alquiler residencial. Scriptanova, Vol. XXI. Núm. 580. DOI: https://doi.org/10.1344/sn2017.21.18573 